\title{
NOT YOUR MOTHER'S CULTURE- SECOND GENERATION TAMIL WOMEN NEGOTIATING TRAUMA AND IDENTITY THROUGH ART
}

\author{
by \\ Ann Satkunam, BA (Honours), University of Toronto, 2016 \\ A Major Research Paper \\ presented to Ryerson University \\ in partial fulfillment of the requirements for the degree of \\ Master of Arts \\ in the Program of \\ Immigration and Settlement Studies
}

Toronto, Ontario, Canada, 2017

(C)Ann Satkunam 2017 


\section{AUTHOR'S DECLARATION FOR ELECTRONIC SUBMISSION OF A MAJOR RESEARCH PAPER (MRP)}

I hereby declare that I am the sole author of this Major Research Paper. This is a true copy of the MRP, including any required final revisions.

I authorize Ryerson University to lend this MRP to other institutions or individuals for the purpose of scholarly research

I further authorize Ryerson University to reproduce this MRP by photocopying or by other means, in total or in part, at the request of other institutions or individuals for the purpose of scholarly research.

I understand that my MRP may be made electronically available to the public.

Ann Satkunam 
Not Your Mother's Culture-

Second Generation Tamil Women Negotiating Trauma and Identity Through Art

Ann Satkunam

Master of Arts 2017

Immigration and Settlement Studies

Ryerson University

\begin{abstract}
This research paper focuses on the Tamil diaspora community in Canada that developed in the aftermath of the Civil War in Sri Lanka. This paper explores the impact of trauma on children of survivors, and how daughters in particular navigate these traumas. Furthermore, this paper analyzes how young women bear the trauma differently from their male counterparts, as women tend to be seen as carriers of culture. These ideas of women as carriers of culture do not afford Tamil women agency - instead they are left without choice in certain situations.

Ultimately, this paper explores if art can be used as a mechanism to release the burden women feel. It uses the interview of eight Tamil women to understand their complex narratives, and to see if they use art as a means to reclaim agency.
\end{abstract}

Key words:

Diaspora, Sri Lankan, Art, Second-Generation Tamil Women, Identity, Cultural Purity 


\section{ACKNOWLEDGEMENTS}

Firstly, I would like to thank my supervisor, Doctor Amina Jamal, for her immense kindness and support during this writing process.

I would also like to thank my parents, Amma and Appa, for their unwavering support and sacrifice that has allowed me to pursue my interests. They have been a constant source of inspiration and without them, I would not have been able to survive this journey.

I would also like to thank Sam, Noel, and Shoban for their encouragement.

Finally, I would like to thank all the women who shared their stories and made this project possible. 


\section{TABLE OF CONTENTS}

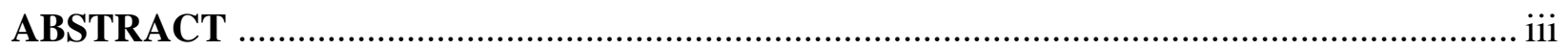

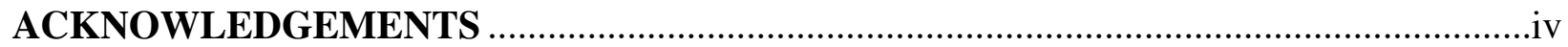

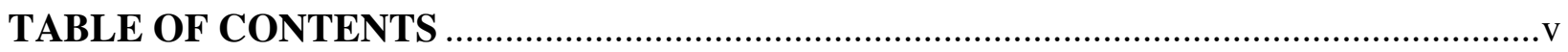

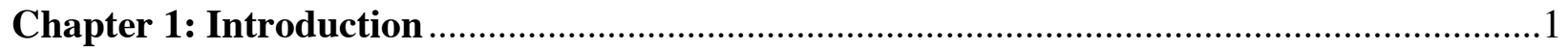

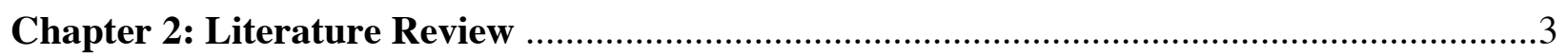

2.1 The Creation of the Tamil Diaspora in Canada ...............................................................

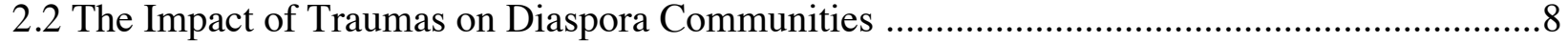

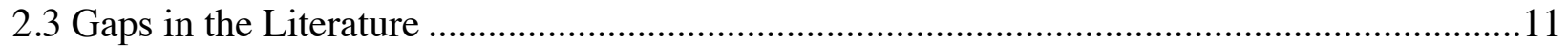

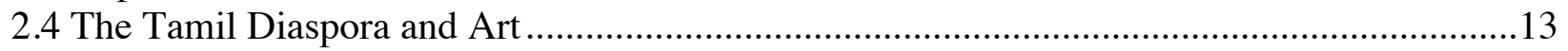

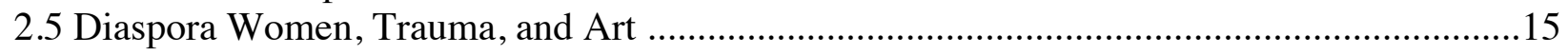

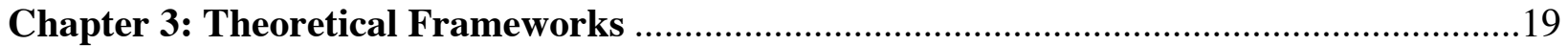

3.1 The Need for An Intersectional Approach ..................................................................19

3.2 The Battle between Modernity and Backwardness .......................................................20

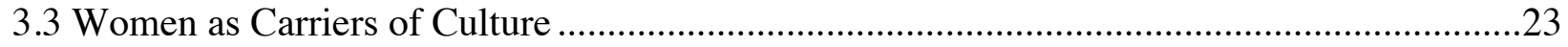

3.4 How to Navigate Two Worlds - Ideas of Hybridity .....................................................26

3.5 Rupturing Colonialism - Ideas of Self-Love................................................................29

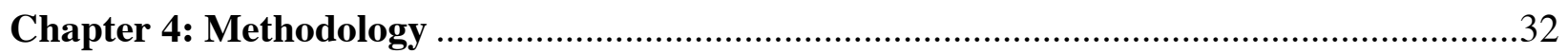

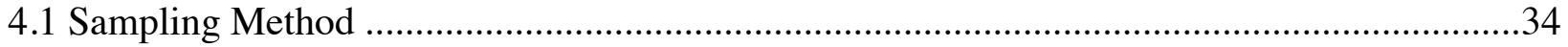

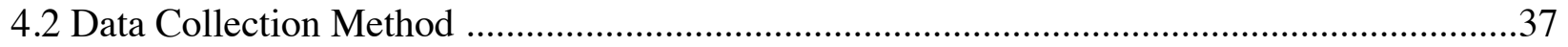

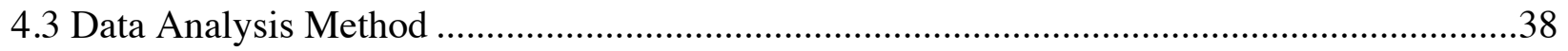

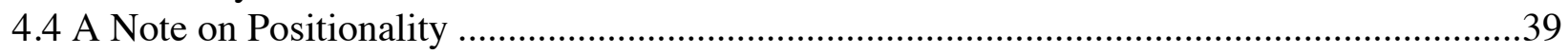

Chapter 5: Participant's Profile ....................................................................................... 41

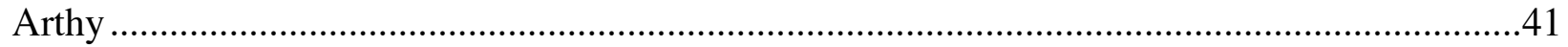

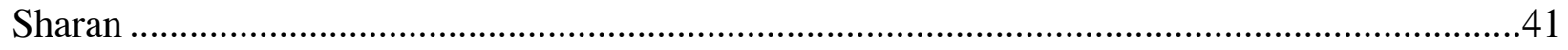

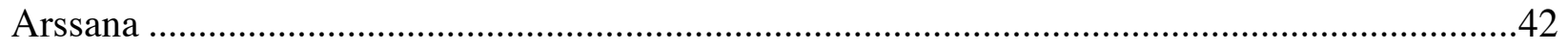

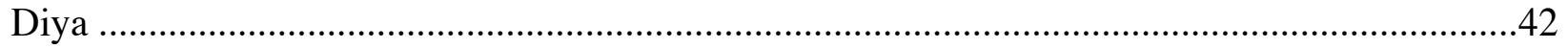

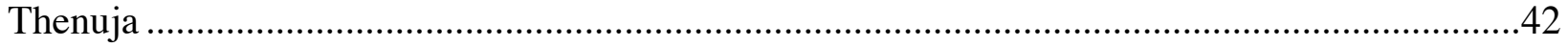

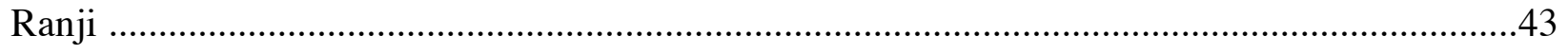

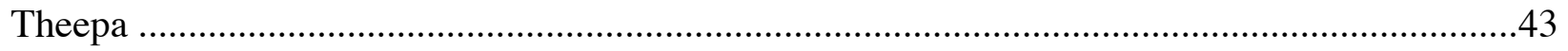

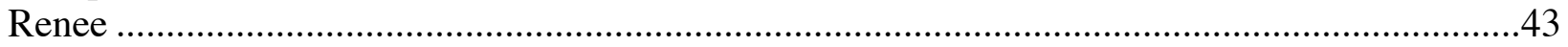




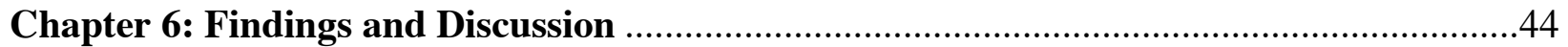

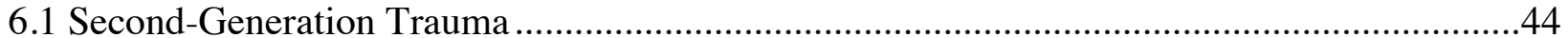

6.1.1 Parents' Silences and Openness about the Civil War ...................................................44

6.1.2 Parents' Expectation for Children ...........................................................................48

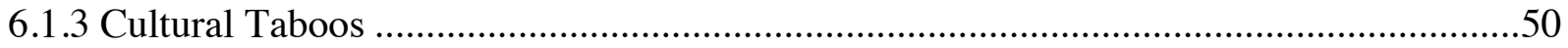

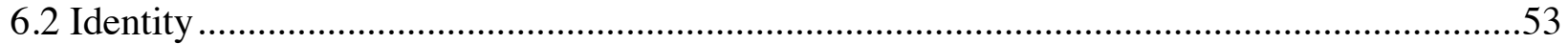

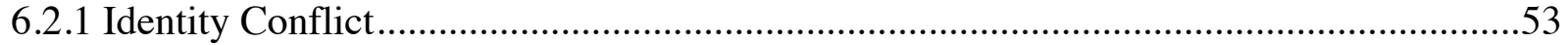

6.2.2 Countering Hate with Cultural Appreciation .........................................................55

6.2.3 Women's Role in the Tamil-Canadian Diaspora ......................................................56

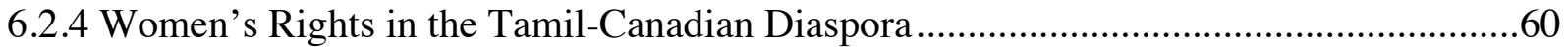

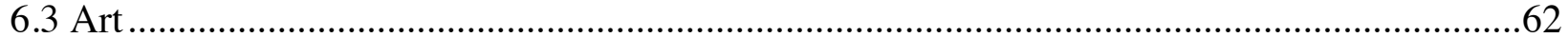

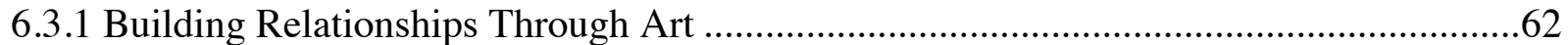

6.3.2 Awareness, Resistance, and Resilience ..............................................................64

6.3.3 Tamil-Canadian Women's Hybrid Identity in Art ....................................................66

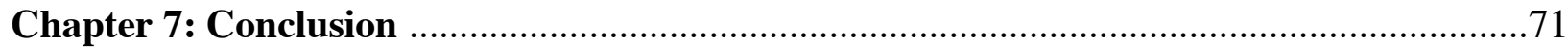

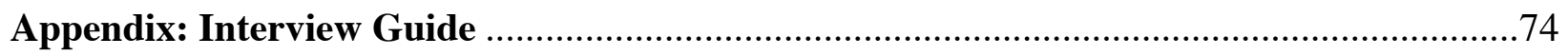

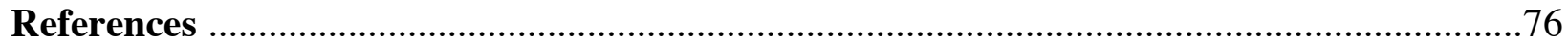

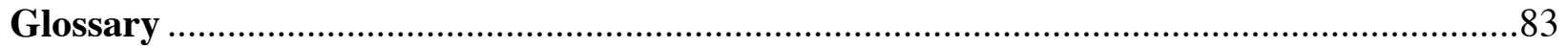




\section{Introduction}

On this side,

I am learning how to stay afloat

Reduced recipes and private poetry are your lifelines

Your family will be everywhere

We've made home wherever our bodies drop

The diaspora includes the dead, drowned, and damaged

They will be easier to forget when they were never remembered

-Renee

The impact of the eradication of Tamil culture in Sri Lanka influences how Tamil

Canadians maintain cultural traditions in Canada. The Civil War in Sri Lanka (1983-2009)

resulted in a large movement of Tamils out of Sri Lanka and into Toronto (Amarasingam, 2015;

Beiser, Simich, Pandalangat, Nowaskowski, \& Tian, 2011; George, 2011). Being a part of a

diaspora is a constant negotiation of home, identity and trauma. The Tamil diaspora in Canada

has been negotiating the experience of traumas as a result of the Civil War, which included the

ethnic cleaning of the Tamil community and cultural genocide at the hands of the Sinhalese

majority (Amarasingam, 2015; “The Legal Case,” 2015). The trauma that Tamil people as a

community experience is "cultural trauma" a kind of trauma that is shared amongst a community

which has encountered violence that they feel has destroyed the cohesiveness of their group,

altered their memory, and ultimately changed the group's identity (Shani, 2010). The cultural

trauma has permeated the fabric of the Tamil community and influenced how the Tamil

community functions in Canada.

One response to the trauma that resulted from these incidents is to maintain cultural

purity. Hall (1994) argues that diasporas generally attempt to maintain the culture as they

remember it from their country of origin, while it evolves in their home country. This burden to

maintain culture essentially falls on women, who are seen as biological and cultural

reproducers - they are expected to have children and teach the children about the culture 
(Anthias \& Yuval-Davis, 1989). Women may have a difficult time understanding and navigating the expectations to maintain cultural traditions that have been imposed on them.

Women's voices are often not heard in diaspora communities (Agnew, 2005) and as a result many women's narratives are lost. Therefore, this study focuses on the voices of Tamil women, as their voices are often lost in cultural and historical interpretations of trauma.

Particularly, it focuses on second-generation Tamil women and how they navigate traumas inherited from their parents and how it influences their self-worth and identity. Hirsch (2012a) argues that memory can be transferred to those who are not there to witness an event. This may resonate with the experience of second-generation Tamil women and how they have come to understand and interpret their parents' interaction with the Sri Lankan Civil War. Renee, one of the participants in this study, wrote the epigraph in the beginning of this chapter. In her own way she is still negotiating the impact of being part of a diaspora, the Civil War, and the violence that plays a role in her life. The study attempts to understand how women find ways to have their voiced heard over cultural trauma and memories.

Since cultural genocide is an important aspect of the violence experienced by Tamil people in Sri Lanka, this paper explores if women have found a means to negotiate these traumas through the use of art. In some ways, the art these women produce can be seen as a tangible means of their resilience and agency. The art can be seen as a ways of presenting their grievances and a means to be heard, when they are largely ignored or at the very least a way for discourse to be started within the Tamil community as well Canadian society. This paper explores if "art can be used as a mechanism to release the burden of cultural purity, as well as a strategy to (re)invent culture where Tamil women can (re)tell and (re)present their story as autonomous beings" (Satkunam, 2017). 


\section{Literature Review}

To understand the narratives of the Tamil women who participated in this project, it is necessary to consider some background information and historical contexts. Therefore, this section explores the term diaspora, gives a historical account of the Sri Lankan Civil War and also outlines the attachments and various traumas that affect diaspora communities. This section also explores how art is significant within the Tamil diaspora and outlines how women navigate trauma through various art forms.

\subsection{The Creation of the Tamil Diaspora in Canada}

Diaspora is a complex word that has evolved to include different meanings in present time. It originates from the ancient Greek word diasporá, and translates to "scattering or dispersal" (Kenny, 2013, p. 3). The word was loosely associated with the eradication of something, including the deportation of communities from cities (Kenny, 2013). The term was then made familiar through the displacement of the Jewish community related in the Bible, and introduced ideas of uprooting, banishment, and nostalgia (Kenny, 2013). It developed an attachment to religious principles, and the word started to revolve around concepts of 'exile' (Ben-Rafeal, 2013 p. 843). The term "diaspora" has since grown and now encompasses various groups of different descent, such as South Asians, East Asians, Armenians, and Africans (Agnew 2005; Hua, 2005; Kenny 2013). It is now applied to many different scenarios and includes ideas of longing, isolation from one's country of origin, a need to return to one's country of origin, a shared trauma, and finally, a shared sense of comradery based on these themes that move beyond borders (Agnew, 2005). Today, these ideas of uprooting and exile are paramount to the term.

The Tamil community faced uprooting due to the Civil War in Sri Lanka (1983-2009), which encouraged a large Tamil population to move out of Sri Lanka to Canada (Amarasingam, 
2015; George, 2012). Differences in ethnicity between the majority Sinhalese and minority Tamil encouraged tensions in Sri Lanka (Amarasingam, 2015; George, 2012). Sri Lanka is home to approximately 20 million people, where the Sinhalese account for about $74 \%$ of the population, and Tamils account for about $12 \%$ of the population (Amarasingam, 2015). The two communities share some similarities; however, they have some notable differences. Their primary difference lies in language and religion, since the Sinhalese community practices Buddhism, and the Tamil community practices Hinduism (George, 2012).

The distinction between the two communities became more pronounced as colonial powers interfered by reorganizing political structures in Sri Lanka ("The Legal Case," 2015). Sri Lanka was under colonial rule for up to four centuries from 1505-1948, and Britain was the last imperial power to occupy Sri Lanka, after the Dutch and Portuguese (Amarasingam, 2015). When the British left, they gave the Sinhalese government power (Amarasingam, 2015; "The Legal Case," 2015). Tensions were exaggerated as the Sinhalese desire to reposition themselves as the island's dominant culture, which they felt had been lost during colonial rule, directly conflicted Tamils' aspiration to safeguard their culture from the Sinhalese community (Kearney, 1985). The restructuring of powers had a lasting impact on the Island's political state.

The Tamil community faced discrimination, and there was a fear their culture would be erased due to the Sinhalese government. Ethnic tensions peaked as discrimination against the Tamils was codified in the Sri Lankan constitution (Amarasingam, 2015). For example, in 1956 the Language Act was passed that cemented the Sinhalese language as the primary language in Sri Lanka, and made the Tamil language inferior (Amarasingam, 2015). The Tamil community viewed the Language Act as detrimental towards the flourishing of their own language in Sri Lanka and interpreted it as a scheme that reinforced the Sinhalese population's power within the 
Sri Lankan community (Beiser et al., 2011; Amarasingam, 2015). To mediate tensions concerning the Language Act, the government decided to pass a Tamil Language Act, under which Tamil can be spoken in certain areas such as the North and East school districts of Sri Lanka (Amarasingam, 2015). However, uneasiness increased when in 1972, there was an introduction of a new Constitution that ensured that Buddhism took precedence in Sri Lanka (Amarasingam, 2015, p. 23). These new laws threatened the Tamil culture and Tamil people's ability to function as a community within Sri Lanka.

In response to these policy changes, Tamil student groups began to challenge the discrimination (Kearney, 1985; Amarasingam, 2015). However, due to differences in beliefs, caste or individual hostility, the student group became divided into approximately six distinct groups (Kearney, 1985). The most prominent group emerged in 1972 called the Liberation Tigers of Tamil Eelam (LTTE), which was led by Velupillai Prabhakaran and had the most significant influence on the Civil War (Kearney, 1985; Amarasingam, 2015). Moreover, in 1976, there was an emergence of a political group called Tamil United Liberation Front (TULF) that demanded an independent state called Tamil Eelam, which was indicative of the weariness and frustration majority of Tamil community felt within Sri Lanka (Kearney, 1985; Amarasingam, 2015). Political and underground groups reflected the restlessness people were feeling within the larger Tamil community.

These fears were further reaffirmed through other violent altercations between the Tamil community and the Sinhalese government. In May 1981, due to violent confrontation between a Tamil militancy group and the Sri Lankan Police, the Jaffna Public Library was burned to the ground by the police officers (Amarasingam 2015). The library was a Tamil cultural hub and housed ninety thousand books, many of which could not be replaced (Amarasingam 2015). This 
act was viewed as "cultural genocide" by the Tamil community, and interpreted as a scheme planned by the Sinhalese government with the intent to destroy Tamil identity within Sri Lanka (Amarasingam, 2015, p. 31). The burning of the library was a catalyst for more violent encounters between the two ethnic groups. Uneasiness continued to intensify and led to "Black July" started on July $24^{\text {th }}, 1983$ when the Tamil community was subjected to a week of violence by Sinhalese rioters (Amarasingam, 2015). During the week, Tamil homes, businesses, or vehicles were burned or destroyed (Hashim, 2013; Amarasingam, 2015). Women were raped and were compelled to display themselves unclothed in front of swarms of people and some Tamil individuals were also set on fire or shot (Amarasingam, 2015). There was no official documentation of the lives lost, but estimations range between 400-3000 deaths, many of them Tamils, and more than 100,000 Tamils were relocated into refugee camps (Hashim, 2013; Amarasingam, 2015). The aftermath of the week manifested into deep mistrust of the Sinhalese by the Tamils in Sri Lanka (Amarasingam, 2015). The violence had lasting impact on the Island, and had dire implications for the Tamil community.

Since the term diaspora has focused on themes such as exile, there is sometimes a large emphasis on an imagined birthplace. Axel (2002) argues the concept of a homeland becomes the defining point for all diaspora communities and often there are debates of what that homeland constitutes of and where these people originate from. However, for some diaspora communities, a country of origin is not a main concern (Axel, 2002). The focus on return to an imagined homeland can overshadow the injustice some diaspora members have faced and negate their struggles. Alternatively, Axel (2002) proposes the term the "diasporic imaginary," which is conceived of two parts - first, ideas of violence define members of certain diasporas. Secondly, it defines diaspora through ideas of existence and tangibility (Axel, 2002). In essence, the diasporic 
imaginary is an identity shared by members and that diaspora members create (Axel, 2002). This idea affords diaspora members agency and allows them to move beyond ideas of return, and reimagine how violence plays a role in their diaspora narrative.

The focus on return can overshadow what led to the movement of a diaspora out of their homeland. For example, for the past 16 years, the Sikh community has been subjected to extreme violence, such as genocides (Axel, 2002; Shani, 2010) and this violence in their diaspora narrative has rarely been told (Axel, 2002). Although ideas of an imagined homeland is important to many diasporas, the violence that members have been subjected to and how they conceive that is just as essential to their narrative. Axel (2002) argues that not everyone in the Sikh community have been subjected to violence, however this narrative of violence has been globally reproduced and has become essential to their identity. In the same vein, the movement of Tamils out of Sri Lanka further exemplifies how interaction with violence affects migrants' relationship with their homeland and how ideas of uprooting may not take into account the violence the Tamil community encountered.

The Civil War in Sri Lanka encouraged many Tamils to leave their homes. Majority of Tamil migrants were influenced by the events of Black July and the aftermath and left Sri Lanka for Canada for the next thirty years (Amarasingam 2015). As a result, Toronto, Canada is home to one of the largest growing Sri Lankan Tamil diaspora communities, numbering 150,000 Tamil people (Amarasingam 2015; Beiser et al., 2011). Since the diaspora community in Canada is fairly new, with most arriving after 1983 (Amarasingam 2015), it means many new Tamil immigrants have been exposed to acts of violence that are fresh in their minds, and they have constructed an imaginary on the basis of the trauma. 


\subsection{The Impact of Traumas on Diaspora Communities}

In discussion of trauma in diaspora communities, the term "cultural trauma" is often used to describe hardship. Some scholars also use the word "collective trauma," and the term will be used interchangeably in this study. Through collective trauma, children of survivors also experience second-generation trauma or "postmemory" (Hirsch, 2012a). This section discusses all three ideas as they relate to cultural memories, and how diaspora communities choose to navigate trauma.

Trauma can move beyond an individual's life, and impact a community as a whole. Trauma occurs when basic human necessities such as safety, stability, and association with other humans have been threatened (Alexander, 2004). On a grander scale, "cultural trauma" is shared amongst a community and arises when a population feels that a violent act has marred the ability to function as a group, altering their memory and changing their identity (Shani, 2010). Some ways a group's identity can be threatened is if a government threatens a group's safety, and the land that a population considers their home is no longer safe (Shani, 2010). Drawing on the Sri Lankan Civil War, the cultural genocide and ethnic cleansing the Tamils were subjected to resulted in a deep mistrust towards the Sinhalese government (Amarasingam, 2015). The Civil War impacted how Tamil culture was able to flourish within Sri Lanka. As a result, the Tamil diaspora in Canada found different mechanisms to overcome their shared trauma.

Diaspora communities may choose to remember a shared trauma that has impacted them. For example, the Sikh diaspora's identity is contingent on how they memorialize their "chosen trauma," the genocides, that were committed against them (Shani, 2010, p 178). Their memory and sense of community have been influenced by the ways they choose to remember these violent incidents. Collective or cultural memory is how events are memorialized through various 
generations (Hua, 2005). These collective memories are documented through various means such as oral histories, written accounts, and cultural activities (Hua, 2005). "Collective memories are the shared representation and knowledge of past social events that have not been personally experienced but collectively constructed" (Hua, 2005.p. 198). The way a nation remembers trauma, or negotiates it, becomes a political act in itself. For many marginalized groups, there is a fight for their narrative to be remembered in opposition to the dominant group's ways of recording history, since the ways histories are remembered can be designed by hegemonic powers to ignore incidents (Edkins, 2003; Hua, 2005). Thus, the way diaspora communities remember their trauma can point to larger political struggles of their narratives being heard over the dominant group's voice.

Collective trauma becomes a shared identity, and it allows diaspora members to articulate pain to those who were not there to experience it. For example, the Sikh community remembers the violence they were subjected to through the Internet, which influences the younger Sikh demographic, who did not witness the violence (Shani, 2010). The representations on the Internet permit the community's sense of "self" to be dependent on the trauma (Shani, 2010). In the same vein, the Tamil community has chosen to remember the genocide of Tamils. This could be seen during the protests organized by the Tamil community in Toronto, especially from January to May 2009, when Tamil people opposed crimes committed against Tamils during the Sri Lankan Civil War (Amarasingam, 2015). These protests, which include children, youth, adults, and seniors, pervade the trauma they were subjected to became a shared experience amongst generations (Amarasingam, 2015). In this way, those who were not there to witness the incident are able to share the trauma, permits diaspora members to reconstruct violence to include other subjects (Shani, 2010). Thus, trauma becomes a shared experience between generations. 
Trauma can both be shared between communities and intimately within families and trauma can be bestowed onto children by parents. These painful memories can be communicated and passed down across generations, and children can inherit traumas their parents or grandparents witnessed (Hirsh, 2012b). Hirsch (2012a) uses the term "postmemory" to describe this phenomenon of children receiving trauma from their parents, and argues that the "post" in postmemory can be seen as akin to Post-it Notes. Posts can be layered on other texts or concepts, which transform the original thought (Hirsch, 2012a). Post-it-notes also have the ability to fall off surfaces, which means some meanings can be lost (Hirsch, 2012a). In this way, “"postmemory' reflects an uneasy oscillation between continuity and rupture... it is a consequence of traumatic recall" (Hirsch, 2012a, p. 6). Children of survivors can reconstruct their trauma to something different from their parents' experiences.

The intimate setting of a home can allow parents to transfer trauma on to children and the closeness of family allows trauma to be conveyed through intangible means (Hirsch, 2012b). Postmemory is an ongoing dialogue amongst generations and how people negotiate traumas and can result in intergenerational trauma (Hirsch, 2012b). Interactions between family members permit collective memories to be shared, and a site where community or generational trauma is discussed (Hirsch, 2012b). "Children of those directly affected by collective trauma inherit a horrific, unknown, and unknowable past their parents were not meant to survive" (Hirsch, 2012b, p. 35). To understand and process that parents have fled and survived certain horrors may affect children of survivors in ways one cannot understand. Thus, children take the trauma of their parents and make it their own and uncover different facets of the trauma they did not realize.

Cultural trauma can manifest in diaspora communities in different ways. An underlying principle of cultural trauma is that the dignity and safety a community provides to its subjects 
have been endangered and its unique identity has been undermined (Shani, 2010). In the face of fleeing a shared trauma, especially one that threatens a community's identity and security, many communities may hold on to ideas of cultural purity. Edkins (2003) argues "some forms of remembering can be seen as forgetting ways of recovering from trauma by putting its lessons to one side, refusing to acknowledge that anything has changed, restoring the pretence" (p. 16). The ways some diaspora communities choose to overcome trauma is to preserve what they knew before the trauma occurred. Hua (2005) argues that in a desire to oppose assimilation into a host country, many diaspora members may attempt to recreate their culture in new countries to ensure their shared history is not lost. The need to protect their culture can be seen as a result of the trauma they faced in their homeland, and the fear their identity will be weakened in a new home.

All of these traumas - personal, intergenerational, cultural, and collective-permeate diaspora identity and influences how people consider or navigate violence. In the case of the Tamil community, they faced a collective trauma by way of ethnic cleansing. The way the Tamil community chooses to memorialize this trauma influences their identity — they developed a culture around protest. Furthermore, this impacts how diaspora communities navigate life in Canada, and how it influences their children. Furthermore, trauma can also lead to a preservation of a culture in their host country that a community had to safeguard in their home country.

\subsection{Gaps in the Literature}

In general, studies on diasporic communities have been criticized for not taking into consideration class or gender differences (Agnew, 2005). This study aims to explore secondgeneration Tamil women's voices in the Tamil diaspora. Literature that discusses Tamil migrant communities in Toronto often focuses on political mobilization (Amarasingam, 2015), and there is a lack of focus on gendered experiences or contributions women made to the Tamil 
community. For example, even when considering the LTTE in the Civil War, often the contributions of women are ignored although women were enlisted into the LTTE since the mid1980s (Alison, 2003; Jordan \& Denov, 2007). At first, women's role focused on propaganda or nursing, however they eventually became soldiers when in 1983, a new unit was conceived called Vituthalai Pulikal Munani (Women's Front of the Liberation Tigers) also referred to as the "birds of freedom" (Alison, 2003; Jordan \& Denov, 2007). In spite of their significant presence in the LTTE, women are rarely spoken about. Thus, the lack of attention to gender and along with a focus on politics erase the other roles Tamil women play in the diaspora, such as documenting oral histories or garnering change around mental health or sexual assault.

A gendered analysis is also necessary to understand how people negotiate trauma because men and women can react and experience trauma differently. Studies that have been generally conducted focus on the post-traumatic stress disorder and migration stress experienced by Tamil migrants (George, 2013; Beiser et al., 2011), without considering the role gender plays. For example, in Hirsch's (2012a) exploration of the Holocaust film Shoah, she argues "women are not simply absent: they tend to function as translators and mediators carrying the story and its affective fabric, but not generating it themselves" (p. 12). It is important for the stories of female survivors to also be documented, as their experiences can be different from me and they need to be allowed to tell their own narrative. Literature often mentions women's experience of the Sri Lankan Civil War in passing, by not explaining how it can impact women and how they negotiate trauma (George, 2013; Amarasingam, 2015). These studies do not do enough to unpack or complicate the differences in gendered experiences in the war.

The focus on chosen trauma in the Tamil community - such as the burning of the Jaffna library or Black July (Amarasingam, 2015), does not contextualize Tamil women's life in 
Canada. Furthermore, studies that have been done on Tamil diasporas and their art making (Kanaganyakam, 2007; Laine, 2015; Shanaathanan, 2015) do not consider second-generation women and the importance of art. The last two sections of this literature review aims to explore how art can be helpful in diaspora, and how diaspora women have used it to overcome trauma.

The focus on political activism also does not consider second-generation Tamil women and the role they play within activism or the Tamil community. The example of the birds of freedoms outlined above, or women's experiences in the Civil War (Alison, 2003; George, 2013) do not consider how second-generation women negotiate their identity within Canada.

Reclaiming women's voices allows a more thorough understanding of how trauma intersects and affects lives within diaspora communities as demonstrated in Sugiman's (2004) "Passing Time, Moving Memories.” By exploring how second and third generation Japanese women navigate the trauma of Japanese internment, Sugiman (2004) worked to dispel notions that Japanese Canadian women were docile in the wake of trauma within their community. Sugiman (2004) uses women's oral histories and their personal letters to explore how they resisted colonial and sexist expectations. Sugiman explored alternate routes of histories to understand the role Japanese women played in the internment. In the same vein, art can point to women's lost voices in diaspora communities. Just as her work was essential in exposing how women navigated trauma and resisted colonial enterprises and violence against the Japanese community, this study aims to grant a voice to Tamil women and to represent a multifaceted narrative that showcases the complexity of their lives and how art is an important tool to overcome and negotiate trauma.

\subsection{The Tamil Diaspora and Art}

Colonial influences and resistance against the Sinhalese majority have influenced the role of art in Tamil culture even before the diaspora. Before the interference of colonial powers, art, 
particularly sculptures, was used as a means to reinforce social and religious roles within Sri Lanka (Laine, 2015). However, due to Dutch and Portuguese and later, British influences, art became associated with the upper class Sri Lankans and those higher in caste that were educated in English languages and customs art became associated with elitism (Laine, 2015). Also, as ethnic tensions mounted in Sri Lanka, art became symbolic of the struggle between the Sinhalese and Tamil groups. Furthermore, as displacement due to the Civil War increased, literature that captured the struggle also shifted (Kanaganyakam, 2007). The Tamil community's relationship with time, space, and land changed, and writing captured the social turmoil the community was undergoing (Kanaganyakam, 2007). In this sense, art in the Tamil community became imbued with colonial interference, the Civil War, and the Tamil community's own internal struggle.

The complexities of Sri Lankan Tamils' resistance to colonialism through art forms are often ignored (Kanaganyakam, 2007). For example, Kanaganyakam (2007) examines a poem written by R. Cheran, “The Elder," written in Tamil and translated by Kanaganyakam. According to Kanaganyakam, Cheran draws on an experience with an Indigenous man. Cheran evokes feelings of familiarity as he draws on a common literary theme-being enlightened by an elder in the community. He also disrupts this sense of familiarity - a stanza in Cheran's poem reads: "Suddenly he appears/ across my path/ Grey long hair/ studded with snow/ eagles feathers around his neck" (Kanaganyakam, 2007, p. 131). Themes of familiarity are juxtaposed against the reference to the snow, an indigenous man, and eagles feathers. Cheran uses both the familiar and unfamiliar ideas to resist and adapt to life in Canada.

Similarly, second-generation Tamil immigrants have found ways to disrupt the Tamil community's and host country's thinking. Tamil artist, Reginald S. Aloysius was born in London in 1974 (Laine, 2015). As Aloysius explored ideas of starting a family, he attempted to find a 
way to balance his British and Tamil identity, and explored ideas of how Tamil identity can be passed down to his children (Laine, 2015). In one piece, there is a Hindu temple in the background and in the foreground he used yellow lines that represented flight routes (Laine, 2015). His artwork began to capture themes of nostalgia (Laine, 2015). His work became a medium to negotiate ideas of identity and what he can offer his children.

Art can be an important medium to overcome ideas of longing, and mediate tensions concerning nostalgia and melancholy. The idea that diaspora communities are simply awaiting return to their homeland fail to consider the layered complexities of migrant lives, like melancholy or nostalgia. Sommer (2004) states "melancholy haunts minority lives, doubled between an undead particular identity and the "new" person, embarrassed (literally burdened) by a former self'"' (p. 8). Melancholy may remind migrants of trauma and what led to their move to the new country. Simultaneously, nostalgia may be intermediately linked with family members, friends or places that are left behind. These memories inform how they perceive life in their host country and also be interpreted as an eventual desire to return home. However, memories, and their art, allow nostalgia and melancholy to marry and (re)create a happy home, or envision the homeland as a place of trauma (Agnew, 2005). The ways diaspora members are allowed to (re)negotiate their memories regarding their homeland can ease their transition to their new country and come to terms with violence committed against their community.

\subsection{Diaspora Women, Trauma, and Art}

Arts are important for women who may not have a voice to negotiate memories. Memory in diaspora communities can be seen through things such as historical accounts, visual arts, or music (Hua, 2005). The ways in which feminist theorists deconstruct "cultural memories" aims to tease out women's voices that have been silenced by men's representations of histories (Hua, 
2005). Hence, art can be seen as resistance to a masculine retelling of a history that silenced female perspectives. Visual arts becomes a method where stories are recorded and can be seen a political statement, like an act of resilience or a retelling of a national discourse (Akman, 2014). Arts are an important tool in diaspora communities, but especially for women who are often overlooked in the dominant narratives of both the nation and community.

Creative mechanisms can be used to facilitate transnational connections, cultural growth, and mediate tensions concerning binaries imposed on diaspora members. Even if artists cannot return to their homeland, their art can be influenced and inspired corresponding with the art communities through modern technology (Akman, 2014). Thus, artists can negotiate between two identities more easily. Members of diasporas have been exposed to two, or sometimes three cultures (Akman, 2014), and art can be a mechanism these women use to marry multiple cultures. Akman (2014) argues that women often participate in many cultures, and new cultural traditions are created through this, which allows cultures to grow differently. Therefore, art can be a connecting force between diaspora members and becomes a tool in which artists can negotiate binaries imposed on diaspora subjects. These binaries include things such as 'here' and 'there' (Handa, 2003a), and art allows diaspora members to mediate these tensions.

Art can be used as a medium to connect people and unite divided community members. Dunlop (2005) states, "home is in our poems" (p. 115). Her art form, poetry, has found means to transcend borders and speak to diaspora members in other countries and her poetry has become a means to overcome differences that may otherwise separate community members (Dunlop, 2005). Art has become a way for people to find common ground. For example, drawing on the Arab diaspora, Akman (2014) argues art became a way to connect women and find a universal 
means to communicate despite their background, socio-economic status, or religious affiliation. Art allows women to find a common ground and explore activism through a creative outlet.

Creating art can be a politicized process and form of resistance and activism. Female diaspora artists often negotiate and understand themes of human rights, political conflict or war through their art (Akman, 2014). Art becomes a way in which politics can be derived, and women who may often be left voiceless can use it as a means to reach a wider audience. Kwestan Jamal Ali is a female Kurdish artist, who fled Iraq in 2003, (Akman, 2014). She states: "I get my inspiration from the plight of women the world over. When I see the suffering around me I feel like expressing myself with a voice in support of all these women, and that voice comes in form of painting. That is why I paint" (Akman, 2014, p. 24). Her work is a tool for her to speak for other women and she gathers inspiration from other mothers who were fleeing Iraq (Akman, 2014). Her art was a way to document a mother's narrative, which might have been lost.

Art can be a tangible mechanism to understand pain or nostalgia concerning attachment to one's homeland. Sometimes connections to homeland move beyond nostalgia and could be more aligned with relief. Hua (2005) complicates attachments to homeland by asserting that sometimes women may not feel as attached to their country of origin as their male counterparts, due to structural oppression, like sexism and violence. Thus, women may not fondly look back on their time in their home country because these sites of memory are often difficult to negotiate and to understand. Shanaathanan (2015) suggests his art is a way he can "materialize... feelings of mutuality, loss and shared dispossession in relation to home" (p. 416). His experiences in the Sri Lankan Civil War inspired him to focus what home means to Tamils that have been displaced (Shanaathanan, 2015). His projects allow people to uncover facets of their identity, and his work becomes a means where people understand, uncover, or negotiate their trauma. 
Art lends voice to trauma that is difficult to articulate, and may be a tool to overcome pain. Shanaathanan (2015) shares a story of a couple in London in 2004 that married in Sri Lanka in 1990 and soon after left Sri Lanka. Before they left, the husband did not visit his wife's family home in Jaffna, Sri Lanka (Shanaathanan, 2015). Using his wife's oral description of the home, he built a miniature replica of it, which is displayed in their living room (Shanaathanan, 2015). This miniature home captures ideas of home, belonging, and (re)constructing memories.

Art can be used as a mechanism to reclaim agency. The replicated home allowed the wife to remember home and share a part of herself. How they chose to display and replicate the model of the home can be seen as an attempt at home making and overcoming trauma (Shanaathanan, 2015). Memory is something that is evolving (Sugiman, 2004; Agnew, 2005) and in this narrative, the memory of her home has changed for the woman. This new narrative is contingent on the wife's memory of the home, since the home was recreated through her eyes.

Shanaathanan (2015) states:

... verbal and visual representations give new agency to the displaced to negotiate the realities of homelessness. The act of memorizing and narrating is not only nostalgic and painful, but also a cathartic attempt to cope in the present. Hence, place making is crucially connected to the act of remembering as well as to forgetting. Aesthetics as a feeling-in-common emerges as a mode of mediation offering agency (p. 420).

Art is a tangible mechanism to (re)create the narratives, and to reclaim agency.

Art is an important mechanism to explore, especially for women who may not have the capacity to make their voice heard. It allows women to come to terms or create a tangible reference to their sites of grief or memory. It is also a way for voices to be heard and allows women a creative means to be autonomous beings. 


\section{Theoretical Frameworks}

Below is an exploration of perspectives drawn from feminist, anti-racist, post-colonial and indigenous thinkers that comprise my theoretical framework. These concepts are tools to negotiate sites of oppressions second-generation Tamil women have been confronted by. Based on the interviews conducted, it is evident women are frustrated by the representation and construction of Tamil women. These constructions include, cultural preservation, the desire to relate to the dominant society, the construction of South Asian women as oppressed, and the Tamil women's voices being ignored by both the Tamil community and Western community. All these constructions has led to the development of self-hate and interfered with the selfconstruction of Tamil women, which is why it is important to consider hybrid identity and ideas of self-love.

\subsection{The Need for An Intersectional Approach}

Intersectionality is an important concept to consider in this study, as the voices of women are often lost and this framework aims to understand how oppression works in an interconnected manner. There are numerous oppressions that are working in people's lives, such as race, class, and gender, and the impact it has on people cannot be separated into different categories (Mann, 2012). Crenshaw (1989) introduced the term intersectionality to explore how oppression manifests in people's lives, and how varying discriminations can work together to further marginalize disadvantaged groups.

Intersectionality is an important to consider for women of colour, since often their unique experiences when dealing with structural marginalization are ignored. When women of colour face sexual discrimination their experiences are inexplicitly compared with the gendered experiences of white women or when they face racial discrimination they are inadvertently 
equated with the experiences of Black men (Crenshaw, 1989). This leaves unexamined how gender and race work interactively to shape a unique experience that may be different from that of white women or Black men (Crenshaw, 1989. "Put differently, the paradigm of sex discrimination tends to be based on the experiences of white women; the model of race discrimination tends to be based on the experiences of the most privileged Blacks" (Crenshaw, 1989, p. 151). Here Crenshaw (1989) is speaking on experiences of Black women, however it can be applied to all women of colour. It is futile to categorize oppression, since to consider there are multiple sites of oppressions that exist simultaneously in people's lives that can impact them negatively (Mann, 2012). Thus, sites of oppression cannot be treated as unique from each other, or ranked on a hierarchy, but rather viewed as interconnected (Mann, 2012).

Intersectionality is important to consider in this project, as the voices of Tamil women are often lost. Intersectionality considers how sites of oppressions, such as race, gender, sexual orientation, or class work to disenfranchise Tamil women, and ignore their experiences within the larger Tamil diaspora. It is necessary to consider how multiple factors can oppress people and disadvantage them; otherwise their experiences will be lost under dominant voices.

\subsection{The Battle between Modernity and Backwardness}

Colonialism has had negative consequences on Tamil people historically and in the present day. Historically, the way colonialism functioned meant Sri Lankan citizens were divided against each other, and colonialism led to an emphasis of ethnic and cultural differences (Hashim, 2013). As discussed in chapter 2, the ethnic cleansing and the cultural genocide Tamil people faced in the aftermath of war had negative implications on their identity. Furthermore, even after fleeing war, Tamil migrants faced discrimination based on fear from the wider Canadian community. 
Post-colonial scholars (Mohanty, 1984; Bhatia \& Ram, 2004) consider colonialism to be an ongoing process that has a negative implication on minority lives and prevents them from being accepted into Western society. The residual effects of colonialism have constructed the minority body as different (Hall, 1994), and have negative implications for migrants and their identity. For example, Bissett (2008), a Canadian diplomat argues that Canada is increasingly susceptible to terrorist attacks, since there are very lax policies concerning religious or ethnic groups. Bissett (2008) states Canada has allowed known terrorist groups, such as the LTTE to function on Canadian soil. These fears have been translated into public discourse-in October 2009, when Tamil asylum seekers arrived by boat, they were greeted with negative media coverage-Tamil refugee's asylum claims were scrutinized and were framed as both illegal migrants and terrorists (Bradimore and Bauder, 2011). These representations of the Tamil community failed to consider the Civil War the occupants were fleeing. Beiser et al. (2011) argue that due to these perceptions the Tamil community has felt they have been treated with bias. The representation of the Tamil community assumes terrorism was brought to Canada by foreign cultures, and refugees threaten Canadian safety.

The construction of the Tamil body as terrorists marginalizes Tamil people from Canadian society, and reinforces binaries that existed from colonization. Binaries such as backward versus advanced assume that other cultures have violent tendencies, while Western culture is more civilized (Handa, 2003a). Said (1978) argues the East "has helped to define Europe (or the West)" (p. 9), or in other words, the West is everything the East is not and without the construction of the East as backward, the West cannot establish itself as modern. Said (1978) emphasizes how colonialism functions in a way that stresses and constructs the West's dominance over the East's assumed backwardness. This sentiment still functions today with the 
emphasis on binaries - the West is constructed as modern, while the East is seen as traditional or the West is advanced while the East is backwards (Handa, 2003a). For example, there would be no modern white women, without the construction of the "third world women" - the women who wear the hijab, or retains sexual purity (Mohanty, 1984). Without the construction of the 'third world women' as oppressed, white women cannot be constructed as women with agency (Mohanty, 1984). White women have been granted the ability for self-representation, while women of colour have been homogenized and categorized as oppressed (Mohanty, 1984). These binaries work as symbolic markers that have come to define the East and West (Handa, 2003b). South Asian women are entangled in this struggle - as young South Asian women's presumed victimhood is often compared to white women of the same age (Handa, 2003a).

According to Handa (2003a), the contemporary sentiment they need to be saved from their own culture is reiterated in the lives of young South Asian woman - who are seen to need modem culture to save them from traditional and strict parents. Thus, Tamil women are perceived to be in need of saving from male terrorists that may harm them, and secondgeneration Tamil women need to be saved from a culture that is rooted in patriarchy. This idea is similarly echoed in white feminism, where the nuanced differences of women from other nations are not addressed, thereby erasing their experiences (Mohanty, 1984). The construction of the third world women takes away women's agency, as women are constructed as passive victims (Mohanty, 1984). The construction of the third world woman is contingent on her identity as a woman or in other words, "sexually constrained" and "third world" or "ignorant, poor, uneducated, tradition-bound..." (Mohanty, 1984, p. 337). The homogenization of women experiences as victims reinforces colonial discourses passivity, and drowns out South Asian women's voices, despite the fact they are speaking out. 
These constructions of women as victims has historical implications - in the larger struggle between the East and West, women become the defining factor of these cultural boundaries constructed by the East and West (Handa, 2003b). Handa (2003b) argues in colonial India, the ways in which women were treated were a reflection of how modern the country was. This form of measurement allowed Britain to assume that since women were of lower status as compared to men, India did not have the capacity for independence (Handa, 2003b). This reinforced ideas of civility and incivility between India and Britain and allowed Britain to justify their colonization of India (Handa, 2003b). The impact of colonialism mean that women bear heightened responsibilities within diaspora communities to safeguard their traditions from the homeland (Bhatia \& Ram, 2004).

\subsection{Women as Carriers of Culture}

As a result of the violence and colonial influences diaspora members face, they may hold onto their cultural identity as a means to overcome trauma. Hall (1994) argues that usually cultural identity is an idea of a shared or a "collective "one true self"" (p. 393). Cultural identity is usually understood as a shared past that unites a community and has the capacity to share similarities, and a "frame of reference" people can refer to (Hall, 1994, p. 393). There is a shared oneness amongst diaspora members (Hall, 1994). This idea of cultural identity is contingent on one's past, and there is a linear understanding of identity (Hall, 1994). Handa (2003b) claims there's a tension between considering culture as static and seeing it as growing. For example, in Canada, South Asian identity is based on certain acts of "cultural preservation" (Handa, 2003b, p. 57). Cultural preservation is using certain cultural markers, based on customs, gender, and historical contexts, to assert boundaries, or to set apart, a minority group in a country (Handa, 
2013b). Cultural preservation becomes a key means to preserve a diaspora identity, and to ensure cultural norms exist within a new country.

A women's sexuality in society can be highly controlled, as it is seen as a key factor in nation building. Yuval Davias and Anthias (1989) argue there are five ways in which women participate in the building of a nation:

(a) as biological reproducers of members of ethnic collectivises;

(b) as reproducers of the boundaries of ethnic/national groups;

(c) as participating centrally in the ideological reproduction of the collectivity and as transmitters of its culture;

(d) as signifiers of ethnic/national differences-as a focus and symbol and transformation of ethnic/national categories;

(e) as participants in national, economic, political and military struggles (p. 7).

These insights may be applied to South Asian women, and more specifically Tamil women.

Women play a fundamental role in nation building as they have the capacity to reproduce and reinforce soft borders for nations (Anthias \& Yuval-Davis, 1989). In other words, in order to protect cultural purity, whom women are allowed to reproduce with is policed (Anthias \& YuvalDavis, 1989). It is essential that women procreate with men of the same ethnicity to maintain cultural customs and traditions so as not to ruin cultural integrity (Anthias \& Yuval-Davis, 1989). Thus, a women's womb can be highly politicized, as her body becomes a site for culture to be reproduced and maintained.

Gender roles that are constructed have enforced certain responsibilities on women. Women are seen as "cultural carriers" and are viewed as playing a principle role in teaching the new generations customs and traditions of their cultural groups (Anthias \& Yuval-Davis, 1989). A woman's body becomes highly politicized in the quest to preserve culture and becomes a site for traditions to be reproduced and policed (Lakshmi, 1997). Lakshmi (1997) argues:

These attempts [to preserve traditions] are born of a need to perceive women as those who authenticate a cultural or a national identity and as guarantors of the purity of this 
identity. Whether it is a struggle for nationhood or a cultural identity, how a woman generates life, how she dresses, how she lives, what she reads - what she does with her body - becomes the most crucial issues of debate (p. 2593).

Women are perceived as taking on the duty of reproducing cultural identity. In this way, the burden of remaining culturally pure can fall heavily on a woman, as she is expected to teach the future generation how to behave. As a result, everything a woman chooses to do can be scrutinized by their community, which can especially frustrate second-generation women, who may want to assimilate, but are expected to uphold values from their homeland.

The burden placed on women to adhere to cultural traditions complicate how women can negotiate can claim agency. In the South Asian community, the ways women behave and negotiate ideas of womanhood reflect their commitment to their community (Handa, 2003b). If women were to transgress cultural expectations, they are sometimes placed in contrast to Western expectations of women (Handa, 2003b). Lakshmi (1997) on speaking of women's expectations in Tamil Nadu in India argues there is a core understanding of what being a woman is. Some of these attributes include being shy, ignorant, or rather, hiding one's knowledge, and being virtuous (Lakshmi, 1997). Bearing in mind, this list is from a song presented in 1951 that Lakshmi (1997) explores, however, it demonstrates the difficulty women face in negotiating their identity. Similarly, Tamil women have been very vocal on an online platform called "tamilculture," where women have written pieces expressing frustration based on roles ascribed to them by the Tamil community. In one piece, Jeyarajsegaran (2016) argues that women's body and their clothing have been highly regulated in Tamil films, and women are demeaned. Jeyarajsegaran (2016) stresses the need for a change within the film industry so women are not represented as passive. This stresses how Tamil women have become frustrated by the representation of their gender in media, and demand change. 
These representations can be particularly trying for second-generation women who are caught between two cultures. For instance, Naber (2011) speaks of these experiences, though she is from an Arab family who settled in San Francisco, there are similarities. The behaviour of women in her community was a direct reflection on how fathers or their families can be respected within the community (Naber, 2011). In Naber's (2011) reflection, she considers how children emulating Western culture were understood as betraying Arab culture. In this way, Naber (2011) states that she was constantly traversing between two worlds. Women particularly are expected to uphold cultural ideals that are sometimes difficult to negotiate or understand.

\subsection{How to Navigate Two Worlds-Ideas of Hybridity}

This focus on women's body and the emphasis on cultural purity ignore the idea that culture evolves. Hall (1994) argues that culture is an organic process and is an act "of 'becoming' as well as 'being”' (p. 394). For example, in terms of African slavery, there was a discontinuity in how African culture is conceptualized in the present (Hall, 1994). It is not possible to preserve culture as one remembers it, or maintain cultural purity, as culture evolves into something else through "memory, fantasy, narrative, and myth" (Hall, 1994, p. 395). The idea of nationhood, which is assumed to be static, is based on transforming concepts of "political, economic, or social goals" (Handa, 2003b). For example, what it is to be American today has changed post-9/11, and much of how Americans perceive themselves is in relation to other countries (Handa, 2003b). The way a culture evolves in a new country can be different from how it is in the country of origin. To ignore organic changes in culture could mean that while diaspora members are frozen in time, the culture in their homeland is becoming something different as to what they imagined.

Hybridity is a process through which one can negotiate identity and challenges ideas of 
purity. Hall (1994) argues: "The diaspora experience as I intend it here is defined, not by essence or purity, but by the recognition of a necessary heterogeneity and diversity; by a conception of 'identity' which lives with and through, not despite, difference; by hybridity" (p. 204). It is necessary for diaspora communities to consider hybrid identity, especially for the retention of culture in younger generations, as they may need to find a medium between two cultures. In order for culture to survive, it must adapt to different setting and ideas of purity are often a myth. For example, a saree, a piece of clothing that is symbolic of Tamil culture, has Greek origins (Lakshmi, 1997). All this to say, it is often difficult to ascertain what Tamil culture and identity is and what Tamil diasporas are working to preserve (Lakshmi, 1997). Cheran (2007) asserts how the Tamil Canadian diaspora differs from those who are in Norway and Switzerland. Therefore, identity can evolve with the host country's norms and assuming that there is one central Tamil identity does not consider how culture can manifest in different places.

The hybrid identity is an important way to consider how second-generation immigrants can find a place in Canada. Cheran (2007) comments on the term Tamil-Canadian, he states: "The hyphen placed in both terms can indicate a particular kind of consciousness - one that is aware of belonging to more than one history and location" (p. 161). The hyphenated identity allows people to marry two cultures together, and claim a space in the Canadian landscape. Moreover, the hyphen emphasizes that identity can be cultivated not only through historical or cultural aspects, however through lived experiences (Cheran, 2007). Additionally, the hyphen stresses how Tamil-Canadians are trying to live life in two worlds (Cheran, 2007). The use of the hyphen allows Tamil diaspora to lend support to those in Sri Lanka, while finding a space within Canada (Cheran, 2007). Therefore, the hyphenated identity allows migrants to make sense of what being Tamil in Canada means. It does not call for assimilation or the preservation of 
Tamil identity, but living in harmony within two cultures.

While the concept of hybridity disrupts the notion of a fixed identity, it does pose some problems. Hybridity ignores how Tamil identity is challenged by hegemonic ideas of a Canadian national culture. In other words, there is a desire for Canadians of European descent to preserve western ideals of national identity despite the claims to multiculturalism (Handa, 2003a). Canada has defined itself as accepting towards immigrants (Fleras, 2015b), and the Canadian government has even codified multiculturalism into policies (Bissett, 2008). However, Canadian's in some ways still view immigrants as a threat and while there are policies of multiculturalism, there are also policies in place that ensure "Canada's sovereign right to define membership”(Fleras, 2015b, p. 76). On asylum seekers, Fleras (2015a) argues: “Claimants whose racialized characteristics do not align with a Canadian norm of whiteness attract additional antipathy" (p. 162). There is an emphasis of protecting Canada from terrorists (Fleras, 2015a), and thereby safeguarding Canadians and Canadian identity as a whole, from those cultures, like Tamils, are perceived as backward. Thus, the representation of Tamil people as illegal migrants or terrorists (Fleras, 2015a; Bradimore and Bauder, 2011), calls into question how much the Tamil community is able to embrace Canadian sentiments and directly undermines Canada's desire to choose who is let into the country.

The power differences between dominant Canadian culture and Tamil culture undermine the construction of hybrid identities. Handa (2003a) argues that: "While Canadian and South Asian discourses of cultural protectionism may be similar, the former, unlike the latter, has the (relative) social, economic, and political power and representational resources to enforce itself" (p. 5). In other words, Canadian identity has the political clout weaken the Tamil identity and influence people to assimilate. For example, if dominant Canadian media outlets present Tamil 
men as terrorists, many people may begin to internalize this idea, and may marginalize Tamil community members further. It may even cause Tamil members, including women, to disassociate from their Tamil identity due to Canadian identity's social clout. The constant navigation between customs, loyalty, or nation may leave immigrants and especially their children in a complex narrative (Bhatia \& Ram, 2004). For South Asian women especially, there is a constant struggle to adhere to cultural customs or to conform to other ideals Therefore, when considering hybrid identity, it is important to reflect which part of the hyphen has the louder voice (Bhati a \& Ram, 2004). The hybrid identity overlooks the idea that there is an unequal power balance between two cultural identities, and which identity has the likelihood of being dominant in the hyphen.

Despite these shortcomings, concepts of hybridity is useful for my study since it can help me understand how identity is multifaceted, and can help mediate tensions for second-generation Tamil women. Despite the imbalance in power, hybridity stresses the importance of the hyphen and a dialogue that occurs between identities (Bhatia \& Ram, 2004). When speaking of "Tamil identity... we are actually talking about the politics of choice; of selectivity; the politics of picking and choosing and perceiving some elements of the culture in a certain way and transforming them into basic elements of an identity" (Lakshmi, 1997, p. 2954). Thus, the Tamil diaspora community can contest tensions between two cultures, and allow second-generation immigrants to reclaim a space within the Tamil and Canadian culture. It is necessary for Tamil people to acknowledge that both identities are always changing.

\subsection{Rupturing Colonialism - Ideas of Self-Love}

One of the ways in which colonialism has a negative impact on colonized lives, is how hate becomes internalized in one's identity. Fanon in "The Fact of Blackness" (1967) explores 
how his understanding of self was influenced by how the white man views him. Fanon (1967) states: "I am being dissected under white eyes, the only real eyes" (p. 87). The colonial gaze becomes a way in which Fanon understands his self-worth and value. Colonization works in such a way that allowed marginalized bodies to view themselves as the other (Hall, 1994). Thus, the colonial gaze affects how young Tamil people view their self worth, as they are constantly negotiating Western ideals to assimilate against the older generation's expectations to uphold cultural customs. Second-generations Tamil women in particular are left in turmoil, as they feel they do not meet standards of either their Tamil or Canadian identities, as demonstrated by the interviews below. It ultimately challenges their ability to truly embrace either their Tamil or Canadian culture.

One way for Tamil women to negotiate internal struggles is to consider the important of self-love. Indigenous peoples ways of teachings on self-love are important to consider in this project, as it reflects on how one can overcome and be resilient in the face of oppression. Simpson (2011), a Nishnaabeg writer, explores how due to colonial violence, she and her community carry shame within themselves. However, Simpson (2011) elaborates:

It is a shame that makes us think that our leaders and elders did not do the best they could. To me, this colonial shame felt like not only a tremendous burden to carry, but it also felt displaced. We are not shameful people. We have not done anything wrong. I began to realize shame can only take hold when we are disconnected from the stories of resistance within our families and existence (p. 14).

Reclaiming one's identity is an act of resilience that can have healing affects and reconnecting to one's past can help overcome trauma. Furthermore, Simpson (2014) considers how one is able to generate meaning through relationships. Thus, by finding and reclaiming a lost identity, it can be an act of resilience.

Bearing in mind Tamil people's encounter with colonialism is a very different, shame 
manifests within the younger generation in similar ways. Assimilation can be a common means of survival for minorities (Bhatia \& Ram, 2004), and this could be a method for younger Tamil people to survive in the face of representations of Tamils in media. By learning and embracing one's culture it can be a healing journey. Simpson (2011) argues that her ancestors resisted by retaining culture, and it is the responsibility of her generation to ensure that they continue to resist by reinforcing their culture. Finding one's roots again is an act if resilience, as it considers how the Tamil identity can act within the frame of Canadian society.

By finding a space in a society that has tried to erase one's narrative it can be seen as a form of resilience. Finney (2014) explores the complexity of Indigenous girlhood, and argues presencing is an important factor to consider in in this narrative and describes presencing as a dialogical process, which includes Indigenous girls' ability to reclaim space and having the ability to build community. 'Girls' everyday acts of presence-avoiding, protecting, contesting, laughing, hoping, dreaming, connecting, documenting, imagining, challenging — are not singular, simplistic examples of rational agency; they are messy, contradictory, inherently diverse" (Finney, 2014, p. 11). Finney demonstrates through this quote being able to live despite trauma, cultural expectation, and colonial interference. Finney (2014) argues indigenous girls can be ashamed of their background, but to ignore this shame can be a disservice to Indigenous girlhood and their narrative. However, Finney (2014) asserts how being able to build friendships with other girls allow Indigenous girls to make themselves and their own narratives visible. Furthermore, This idea of presencing is important to consider in terms of Tamil woman and by finding a place in society and simply existing, it is an act of resilience. Both colonial forces and violence worked to erase Tamil women's voices, however they persist. Furthermore, by existing together and uplifting other women, these women find a platform in society to be heard. 


\section{Methodology}

This study has been influenced by feminist modes of thinking with emphasis on concepts such as reflexivity, positionality, subjectivity, and personal narratives. Harding and Norberg (2005) assert often good research is presented as a pursuit that is objective, however this is often not feasible. Researchers are inspired by outside factors that influence the outcome of their work, and are not willing to consider how subjectivity plays a role. In this way, feminist methodologies are different from scientific pursuits, as it considers the role and value of subjectivity. Haraway (1988) states objectivity threatens “our 'embodied' accounts of the truth" (p. 578). Thus, it is important to consider how one's experience can influence a study.

In feminist qualitative research, scholars consider the importance of reflexivity. Reflexivity is the process of reflecting on one's own biases that include political, intellectual, or personal during the research and writing process (Doucet, 2007). Doucet (2007) uses "gossamer walls" to consider how reflexivity functions and influences how researchers think. The walls are used as a means to illustrate reflexivity and transparency (Doucet, 2007). The first gossamer wall a researcher encounters is their relationship with themselves, and how this inner dialogue can influence the ways their research is conducted and processed (Doucet, 2007). Below is a note on my subjective position, and how it may affect the work that I did. The second is the relationship the researcher creates with the participant, which can ultimately change "theoretical and epistemological dimensions" (Doucet, 2007, p.73). This second wall grants a greater responsibility to the researcher-they may be obliged to do multiple readings of transcripts to understand what the participant is trying to say and how their own narrative may influence their work (Doucet, 2007). This is important for me to consider, as a Tamil woman interviewing other Tamil women, my interpretation of it may be coloured by my own personal experiences and 
opinions. The ways I consider these women's dialogue and choose to present it is important. Finally, the third wall is the relationship between researcher and the reader (Doucet, 2007). There is a responsibility on the researcher to consider how the work they create may be interpreted by their readers (Doucet, 2007). In this way, in this piece of work, there is an evolving dialogue between these women, and myself. This forces me to consider the ways these women would want to be presented. Feminist thinking is important as it forces the researchers to consider how their participant's information is considered and represented. In this account of these Tamil women, I hope to give them a space where their narratives allow them to reclaim agency, and have their narratives heard.

This study places an emphasis on the personal narratives or oral histories of these women. History aims to present evidence, however the ways these stories are often represented are “cold," using facts or numbers (Hartman, 2008; McKittrick, 2006). In an attempt to be objective, the representations of histories become faceless and voiceless. Further, people in dominant projects have a difficult time understanding how privilege works to their advantage, and how it impacts their work (Harding and Norberg, 2005). Often, these types of research reassert the dominance of systems of oppression (Harding and Norberg, 2005). The voices of the marginalized are sometimes overlooked in dominant research discourse. The use of oral history in research is a means where the interviewees' narratives are emphasized and involve the use of open-ended interviews (Leavy, 2011). Second-wave feminists use the method of documenting oral histories in an attempt to allow marginalized people's narratives to be the dominant discourse within the interviewer's work and aims to elevate marginalized people (Leavy, 2011). This study focuses only on the voices of women in an attempt to reclaim agency. Often women are ignored in the documentation of memories (Hua, 2005). Cixous (1976) posits: 
...writing has been run by a libidinal and cultural - hence politically, typically masculineeconomy; that this is a locus where the repression of women has been perpetuated, over and over, more or less consciously, and in a manner that's frightening since it's often hidden or adorned with the mystifying charms of fiction; that this locus has grossly exaggerated all the signs of sexual opposition (and not sexual difference), where women has never her turn to speak... (p. 879).

Female voices have often been ignored, or overpowered by men and their perspective. It is important to consider the stories women have to tell and how oppressive forces work to take away women's voices. The ways in which women may negotiate their identity, or overcome their trauma may be different in how men navigate these problems. This study attempts to consider the second-generation women's voices, and the knowledge they carry with them, and how they dismantle oppressive frameworks through their art.

Below is a discussion of how this study was conducted, and the ways conversation was facilitated between interviewer and interviewee. The chapter outlines the sampling method used, recruitment strategies, data collection, data analysis, and describes the researcher's positionality.

\subsection{Sampling Method}

The study recruited seven second-generation Tamil women from the ages of 18-35 from the Greater Toronto Area (GTA). Toronto has one of the biggest Tamil diaspora in the world (Amarasingam, 2015; Beiser et al., 2011) and the study limited itself to the GTA in the belief that there is a plethora of resources within Toronto. Since it was necessary for these women to sometimes share uncomfortable memories, and they needed to have the maturity and language to speak to their experiences, the study aimed to find young women. The women were either born in the GTA, or came to Canada between the ages of 0-7. The study focused on this age range due because the Tamil diaspora is fairly new, and most Tamil immigrants arrived after 1983 (Amarasingam, 2015), thus I did not want to exclude people's narratives from the story. The participants that were recruited demonstrated an attempt to fuse Western and Tamil cultural 
influences, rather than demonstrating a strict adherence to what is considered to be a 'traditional' or 'pure' art form. It was important that they explore both Western and Tamil culture, as I wanted to explore hybridity. Many female Tamil artists may choose to pursue traditional art forms, such as Bharatanatyam or Sangeetham, but may observe strict traditional rules out of respect to the art form and customs come with it. Though women who pursue art in a traditional form may also use it as a form of resistance or awareness, this study aims to understand ideas of hybridity, and how women can negotiate Tamil and Canadian identity through art.

The word "second-generation" is used loosely in this study. In an attempt not to exclude the narratives of women who came from a younger age, the scope of word was widened to include children that arrived in Canada from the ages of 0-7. Second-generation immigrants are those who have at least one parent who is an immigrant (Rumbaut, 2006). Those who arrive to a new country between the ages of $0-5$ is generation 1.75 , they are usually children that do not retain memory from their homeland and their experience within their host country closely emulates the experience second-generation migrants have (Rumbaut, 2006). Those who arrive to a new country between the ages of 6-12 are considered generation 1.5 , generally they begin their education within their home country, but have finished their schooling within their new country (Rumbaut, 2006). This study chooses to use the word second-generation through the text so as not to exclude important narratives.

The participants were recruited through the snowball sampling method (SSM) and purposeful sampling. Two women were recruited at an event hosted by a Tamil organization called Abuse Never Becomes Us (ANBU). I approached the women and gave a summary of the study and they consented to the study once more information was given at a later date. SSM is a method used by researchers to access a specific demographic that may be marginalized or 
difficult to access (Atkinson \& Flint, 2001; Cohen \& Arieli, 2011). Participants in this study were difficult to recruit since research subject were required to meet specific criteria. For example, it was difficult to find women that were using Western influences in their work, or women who embrace art forms that are considered Western, such as photography, which is male dominated in the Tamil community.

In this way, the first two women allowed access to resources that were sometimes difficult to find. Furthermore, SSM allows the researcher to use established relationships to build rapport with newer participants (Cohen \& Arieli, 2011). In some ways, having access to the first two women gave validity to this study, and made people more willing to speak to their experience. One woman posted about my study on a Facebook group for Tamil artists. The other woman posted a photo of me on her Instagram profile, and expressed the importance of this study to the larger Tamil community and why it was necessary for female voices to be heard. These two women reached out to others to participate and gave me access to their network.

Despite the positive attributes tied to SSM, there is some criticism too. SSM is often criticized for strong reliance on the first participant interviewed, and data is only drawn from a particular network that represents a unified community, thereby ignoring any outliers in the sample (Atkinson \& Flint, 2001; Cohen \& Arieli, 2011). A way to combat this problem is to not rely on solely on SSM (Cohen \& Arieli, 2011). Thus, I chose to interview one other woman I found through the first two women. I specifically chose to speak to her because she was a Tamil Christian woman, and since all of my other participants were Hindu, it would help diversify the types of research subjects that were in my study.

The other method I used was purposeful sampling, which is a popular method used in qualitative research (Palinkas, Horwitz, Green, Wisdom, Duan, \& Hoagwood, 2013). It is used to 
gather information from selected "information-rich cases" that allow the researcher to utilize restricted data effectively and glean information from a smaller sample (Palinkas et al., 2013; Patton 1990). Furthermore, individuals that are recruited have knowledge or experience that speaks to the circumstance of the study (Palinkas et al., 2013). In this study, I specifically, five of the women were found through Instagram who displayed both their Tamil and Canadian identity. In an email I sent them the intent of the study, criteria to participate in the study, and what I hope to explore in these interviews. If they were interested I sent them the consent form to review.

Additionally, in purposeful sampling, it is important that participants are not coerced into participating in the study (Palinkas et al., 2013). The women were reminded of their voluntary participation in the study, and if they did not want to take part, they were not forced to reconsider. This was especially important to be respectful of their wishes since the study asked sensitive questions that may have made them feel uncomfortable. In order to mediate their discomfort during the interview, I ensured they knew participation was voluntary and they could skip questions or stop the interview if necessary. Purposeful sampling and SSM were the preferred methods to gather participants, since it was a difficult demographic to access.

\subsection{Data Collection Method}

Participants were asked to take part in a semi-structured study for this interview. Each interview lasted between one to two hours. The interviews took place in a private study room at the Student Learning Center at Ryerson University. All of the participants consented to being audio-recorded. Participants were also asked if they would prefer a pseudonym or not. I gave them this option because I wanted them to freely express themselves how they deemed fit.

Semi-structured interviews are the most popular form of data collection in humanities and social sciences (Brinkmann, 2014). In this interview method, it is easier for a dialogue to develop 
between the research subject and the researcher and is especially useful in having rich conversations that one may not glean from structured interviews or surveys (Brinkmann, 2014). In this study, it was essential for it to be semi-structured interviews so women can express their stories, and have their voices heard. In the beginning of the interview, consent forms were given again. They were initially emailed a copy before the email, and the women were given a chance to peruse the form again and sign it. The participants were reminded again of the voluntary nature of the interview. The interview went at a pace the participant felt most comfortable, and if signs of discomfort arose, there was a gentle reminder of the voluntary nature of the interviews.

This project used an interview guide. Since the semi-structured interview method allowed for conversation, I was not limited to the questions in the interview guide (Brinkmann, 2014). The guide allows interviewers to probe participants, whilst keeping within the scope of the study (Alshenqeeti, 2014). The guide was very helpful since it allowed me to focus my questions to my study. The interview consisted of mainly open-ended questions. The use of open-ended questions was important, because it allowed women to freely speak of their experiences. The questions were divided into six main categories: they were asked biographical questions and questions about their art form, relationship with their parents, how their parents navigated their memory of the Civil War in Sri Lanka, the Tamil diaspora community in Canada, and how their identity evolved through the years.

\subsection{Data Analysis Method}

Before data was analyzed, they were transcribed. In the consent form, participants were asked if they would like to have a transcribed copy of the interview. Seven of the eight women asked for a copy of the interview. Saldaña (2014) stresses the importance of researchers to verify the data that is collected from interviews. If participants indicated they desired a copy of the 
transcript, a copy was emailed them to be verified. This was an important step to ensure that whatever the participants wanted to convey was accurately and adequately done do.

The data was then analyzed for themes that emerged throughout the text. In Qualitative Data Analysis (QDA) a way to deconstruct data is "to theme" as described by Saldaña (2014). The interviews conducted resulted in rich conversations, and as a result there were many themes that arose. This method uses phrases to showcase and analyze what data that can be both visible and hidden (Saldaña, 2014). The transcript was analyzed for larger themes, throughout the text and then sub-themes were found (Saldaña, 2014). For example, one theme that emerged throughout the texts was identity - the data was then further divided into subheadings such as hate surrounding skin colour or cultural hate. This method was especially useful in seeing how similar themes emerged throughout the various different interviews.

\subsection{A Note on Positionality}

This study is important to me because of my own interactions with the Tamil community as a second-generation Tamil woman. Oftentimes, as a young person, it was difficult for me to navigate my identity as a Tamil Canadian, and it impacted how I viewed and appreciated my culture. Further, both my parents fled the Civil War in Sri Lanka, and it was only as I grew older, I could see how these traumas affected my household in the ways we chose to remember the war and through my parents' own silences. My mother's narrative has especially influenced how I choose to remember my parent's stories, as most of her siblings are still living in Sri Lanka. Her nostalgia and longing was passed down to me, and how I came to envision Sri Lanka. Sugiman (2004) in her narrative of the Japanese Canadian internment, shared how her family avoided questions that had to do with the interment, and how she felt she could not enquire due to the trauma it may cause her family. Sugiman (2004) expresses how her mother shared her stories of 
the "internment through her caution" (p. 59). This impacted how she was raised and how she understood her parent's story. In the same vein, my own interactions with my parents were similar and sharing their story with me was difficult for them. From a young age, my parents enrolled me in musical classes albeit not a traditional Tamil art form, and it became a way I could start conversations with them. These classes and performances became an important way to talk to my parents. It was through these interactions and observations of other Tamil women I became curious how art can be used as a mechanism to heal relationships and mediate trauma.

Sugiman (2004) posits that her own memories and exposures to the interment stories had influenced how she understood the narratives that second and third generation JapaneseCanadian women chose to share with her. Furthermore, her status as a Japanese-Canadian woman allowed women she was interviewing to share secrets with her-her race became a source of comfort for them (Sugiman, 2004). Comparably, my identity as a Tamil woman may have made it easier for women to share their stories with me. Sugiman (2004) also claims to not be actively distant from the research material. Similarly, my own interactions with my parent's memory have influenced how I created dialogue between these women and myself and how I (re)create these stories. Also, the stories I carried with me made it easier for these women to share their own grievances. These Tamil women's stories are necessary since they expressed being ignored and silenced within the Tamil community, and overlooked by the Canadian community. Anzaldúa (1981) urges women of colour to write in an effort to dispel stereotypes constructed by white people. She further posits, "We cannot allow ourselves to be tokenized. We must make our own writing and that of Third World women the first priority" (Anzaldúa, 1981, p. 168). It is important for marginalized women to share and construct knowledge together to reclaim our voices in our own communities and Canadian society. 


\section{Participant's Profile}

The participants in this study are all second-generation Tamil women who pursue an art form that fuses both Western and Tamil traditions. The women were all born in Canada, or arrived in Canada between the ages of 0-7, and have primarily lived in the GTA while also having attended school there. The following section gives a more nuanced account of these women's narrative, such as: their familial relationships, religious practices, and education. It also outlines which art form their parents enrolled them in, and what art form they ultimately pursued.

\section{Arthy}

Arthy is a 22-year-old Hindu woman who was born in Montreal, but moved to the GTA at the age of two. Her father is the predominant household earner and her mother is a homemaker; she is close to her parents and her sister. Arthy is currently pursuing a science degree. Both her mother and grandmother pursued a musical background. After being enrolled in violin classes and quitting, she asked to be enrolled in Veena classes with her sister, and still pursues art form. She plays Western music on her Veena and uploads it on her Instagram page. She started taking Miruthangam class, a predominantly male art form, to improve her tempo.

\section{Sharan}

Sharan is a 23-year-old Hindu woman and has one younger sister. She has a troubled relationship with her parents because her father is an alcoholic. However, her relationship with them improved after choosing to move out. At a young age, her mom enrolled her in Sangeetham and traditional violin classes, but she quit. Recently, having experienced a racist encounter working at a retail store she worked at, inspired Sharan to use fashion to facilitate change. She uses South Asian and Western clothes to capture people's attention and facilitate discussion about Tamil women. 


\section{Arssana}

Arssana is a 24-year-old woman who lived in Sri Lanka for four to five months when she was 12 . She has one younger brother, and has a complex relationship with her parents. She has a background in South Asian studies and Psychology, which she feels effects how she views her parents and her art. She acknowledges how both her parents have changed throughout the years - her father was strict but has mellowed down throughout the years and her mother was a submissive wife, but she has become more assertive. Arssana is a photographer and painter, but currently gravitates towards photography because it is the most convenient medium to express herself. Her work confronts societal issues such as the sexualisation of women's bodies.

\section{Diya}

Diya is a 27-year-old photographer who was born in Denmark and moved to Canada at the age of three. At a young age, her mother enrolled her in Bharatanatyam, vocal, and traditional violin lessons. She quit Bharatanatyam, but continued vocal and violin until she was 18. She has one younger sister and lives with her mother and grandmother. Her relationship with her parents is troubled-she is estranged from her father and she does not relate to her mother, however, she is close with her sister. She initially thought she wanted to be a speech pathologist, but after struggling with depression upon completing her undergraduate degree, she pursued drawing. Today, she is interested in photography or cinematography. Her work confronts themes such as sexism and showcases the resiliency of Tamil women.

\section{Thenuja}

Thenuja is a 21-year-old model. She has one older sister that she looks up to and she is also very close to her parents. She was enrolled both in Bharatanatyam and Sangeetham, but stopped in the tenth grade because of school. She is pursuing a degree in Human Resources and 
does modelling on the side. Through modelling, she has become more extroverted. She stresses that her work has allowed her to learn to appreciate and keep in touch with her Tamil culture.

\section{Ranji}

Ranji is a 23-year-old Hindu woman, a freelance makeup artist and a Bharatanatyam dancer. She has one younger brother, and is close to her mother. Her father also supports her in her artistic endeavours, as long as she maintains a stable job. Her Bharatanatyam classes helped her to learn more about her Tamil identity and now she teaches it to younger children. She dances Bharatanatyam to Western music and tries to incorporate both her identities in her work.

\section{Theepa}

Theepa is a 33-year-old photographer and fashion blogger. She was born in Sri Lanka, but moved to Canada at the age of seven. She is now married. She has two younger sisters - they were also born in Sri Lanka and one younger brother, who was born in Canada. When she was younger she had difficulty navigating her parents' expectations for her to be a doctor. She ultimately chose to become a photographer, although she hid it from her parents at first. She is inspired by both her mother's fashion sense and her ability to draw. In her work, where she styles models, there is a fusion of Western and Tamil elements, and aims to provoke discussions.

\section{Renee}

Renee is a 19-year-old Christian girl who is pursuing engineering in school. She was born in Canada but moved to Bermuda when she was three months old and returned to Canada at ten. She has one older brother that has moved out. Her relationship with her parents is complicatedher father is an alcoholic and that is a strain on the family. At a young age, her parents enrolled her in classical Western piano classes, but she now writes poetry. Her poetry tackles themes pertinent to the Tamil diaspora communities, such as, suffering, and sexism, among others. 


\section{Findings and Discussion}

The following section is organized according to themes and sub-themes that have emerged through analysis of the interviews. Predominantly, three recurring themes emergedtrauma, identity, and the use of their art. Under second-generation trauma, sub-themes of parents' silences and openness about the civil war, parents' expectation for children and cultural taboos emerged. Under identity, subthemes of identity conflict, countering hate with cultural appreciation, women's role and rights in the Tamil Canadian Diaspora emerged. Under art, subthemes of relationship building, awareness, resistance and resilience facilitated through art, and hybridity emerged. These sub-themes that arose from trauma and identity helped to influence and inspire Tamil women's art, which in turn, allowed them to have a creative release for their own trauma and which became a tool to negotiate their own identity.

\subsection{Second-Generation Trauma}

\subsubsection{Parents' Silences and Openness about the Civil War}

During these interviews, some unexpected themes emerged that pertained to Tamil women's experiences and the negotiating of their parents' trauma. These women had inherited trauma from their parents in some way, but not all of them were as a direct result of the Civil War in Sri Lanka. Some of the women spoke of how the traumas manifested in their parents' life and how parents negotiated it at home. When prompted on how the Civil War was discussed, there was a mixed response on the parents' openness and silences; however, all of them stressed the importance of knowing their parents' story and what their parents faced. Furthermore, in these answers, there was an emphasis on postmemory, and how these women began to capture and negotiate their trauma on their own terms. 
Renee spoke about the frustration she had with speaking to her mother about her story. She shared how it was only when she came back from Bermuda and participated in protests did she become curious about the Civil War. When she pushed her parents further to share stories about the war, her parents were not willing to engage in conversation with her. Renee found out her mother came on a boat to Canada, however when Renee prompted her further, her mother would not open up to her. Beiser et al. (2011) argues that often refugees are not confined to one singular moment of trauma, there are multiple issues that traumatize and impact migrant lives, including the resettlement process. Thus, in some ways, it may be a mother's coping mechanism to protect her daughter from pain. Renee is aware of how these traumas can affect her parents, and claims:

I want to know, but I know it is selfish to pull that out of them, like it's not my story, not my experience. Uhm, I think like I want... there is like privilege in not knowing, because I don't have to face a lot of the trauma they have, but I think it's also this ambiguous "Who am I?" kind of place, where I want to know. Yeah...

Hirsch (2012a) on second-generation trauma asserts that in some sense adopting parents' trauma may be interpreted as immoral. In some ways, the trauma itself can be adopted in a selfish manner, since there is an urgency to relate to loved ones. However, in the same vein, the residual affects of these traumas have a lasting impact on children of survivors. Postmemory is essential to consider because it explores how children take survivor's trauma and makes it their own. Renee later on states:

...like I think in high school where I wanted to know a lot more, that's where identity issues and what not came up. Uhm, it like kind of maddened me, that like they wouldn't talk about it. But, then I grew to understand it's hard to talk about. I think they still try to objectify the war, and try not to make it personal. They uh, cause I know that once they make it personal they have to carry a lot of pain with that, uhm, yeah.

Renee was aware of how these silences impacted her negatively, however she was also aware of how the stories were uniquely her parents' personal narrative. Most of these women carry this 
level of understanding of how these traumas may have permeated their parents' lives and did not want to upset them.

In the same vein, Arthy expressed some discomfort by her parents' reaction when she first visited Sri Lanka. She was eight-year-old when she went to visit, and it was then that she began to learn about the Civil War in Sri Lanka. She shared this story:

When we uh... went through customs ... okay... it was like a lot of questions more than we came through customs in Canada, even as a child, I would see my parents kind of get tensed like when the army... like they were all army ...they were all like military people... it was like very strict and they didn't want like... they would check me as a child too...but they made it a big deal... and it wasn't because I knew what was happening, but it was because I saw my parents reactions to everything, whenever we had to like cross a certain region or whatever, it was still very monitored, I think... when we went to Jaffna too.

Even though her parents were careful not to share too many personal stories of the Civil War with her, she recalls learning to be afraid based on her parents' reaction. She realized the seriousness of passing borders watching her parents and how they navigate the situation. Her sense of safety was tied to how well her parents coped with the army.

Thenuja stresses the importance of listening to her parent's stories, and how these stories have has impacted her.

...[My dad] was big on the whole war thing...He didn't take part of the war or anything, but his family was affected a lot. Like, I know one time, the day my mom and dad were going to get married, no not get married... but they were meeting, bombs going down, and they had to hide in bunkers. Things like that, they told us a lot about it... I don't know why I am getting emotional... I'm sorry... Yeah I just feel like yeah, they just went through so much and they have seen so much... they told us these stories... Uhm... Like, we went to back to Sri Lanka, we were really young, and we don't really know what has changed and what hasn't but, I think now me and my sister will never go back to Sri Lanka, because it is just not the same like, how [my parents] lived or grew up in their houses. Like, a lot of people go back to Sri Lanka now and they stayed at resorts that have been built over bodies and stuff, so I think that there are a lot of things people need to know. And parents don't acknowledge that to their kid, even though it is really hard to talk about it but you should know why you came to Canada in the first place, right? 
She has come to find through her parents' stories that she herself cannot go back to Sri Lanka, even though her parents are willing to. She states that she does not feel comfortable returning somewhere that never wanted her to be there at all. In some ways, her parent's attachment to the diaspora movement here, as well as the protests she attended, has allowed her to grow more appreciative of Canada, while distancing herself from Sri Lanka. In light of this, she emphasizes the importance of knowing why children should know about their parents' story, as it helped her understand and grow closer to her parents.

Similarly, Theepa who was seven when she and her family fled the war, have parents who are willing to speak to her about their experience in the war. She also acknowledges the importance of asking questions, since their stories may be lost soon.

Uhm, well I think I ask more questions, because my parents are getting older I also realize that all those stories are going to be lost when they are gone, so I do ask a lot more questions, whereas my siblings don't. But, I don't think the conversation changes; I mean, my dad tells me certain things he wouldn't tell my siblings. But, I think it's because I am married and he sees me as an adult, so he can share certain things with me and not them. Like, he told me when he was younger my mom almost got raped by an army man, I don't think he shared that with them, I think he would be very uncomfortable sharing that, but he shared that with me very openly. So stuff like that.

She also asserts how her status as married woman may have given her some privilege in speaking to her father. Furthermore, through the course of this interview, she discovered that she mainly speaks to her father about the war, and she is not eager to hear her mother's narrative.

Throughout these interviews, another recurring theme that emerged was their appreciation and awe of their parents' resiliency. These women came to value and even try to understand their parents' narrative once they had a more grounded understanding of the Civil War; this is important to consider as it allowed these women to bond more easily with their parents. Ultimately, they were so thankful and exhibited pride when speaking about their parents' ability to survive and provide for their children in a foreign country. 


\subsubsection{Parents' Expectation for Children}

One of the grievances women shared was their parents' expectations for them and how it affected how they viewed themselves. Most of these women had to uphold expectations parents had for them based on cultural ideals and education. At the same time, their parents' behaviour was policed by the potential backlash they might receive from other community members, as well as through the conditioned collective memories of the Civil War.

The Civil War influenced what kind of careers children were permitted to pursue. The residual effects of the Civil War left families in fear for their socioeconomic safety, which translated into pursuing arts as a professional career being frowned upon (Laine, 2015). Despite the fact all eight women were enrolled in some kind of art form by their parents, none of the parents wanted their children to professionally pursue it. For example, when Diya and Theepa first started photography, they hid it from their parents. Diya explains that her parents chose to enrol her in traditional art forms to uphold a cultural standard and to compare her to her cousin's achievements. These expectations to uphold cultural standards have had a negative impact on all these women, for example, Renee claims:

Yeah, I think I still struggle with it. I am still not perfectly okay with my idea of myself, just because I don't care about pleasing people as much as my parents, I really want them to be happy with me. Not all the time, but sometimes I just want them to be proud of me and know that I am trying my best, but not just because I fulfill a standard, I don't want them to be proud of me because I fulfill $a$ standard. I want them to be proud of me because I work hard. Like, I am doing as much as I can.

Sharan shared the same sentiment; her parents had forced her to pursue a degree in mathematics, which frustrated her. She eventually found a way to make her parents happy with her degree in social work, by asserting her independence. However, she claimed that keeping up with her parents' overall expectations was difficult: 
... as strong as I can be, or anyone can be, like, be comfortable in their skin, it is very hard to be comfortable in our own skin when your parents do not accept it, because your parents made you. So, when you don't live up to the expectations your parents have for you, it sucks. Especially when they compare you to other people, I think that is the most hurtful part, I am sure they do not mean to do it, but it's just sucks. Like, why can't you talk about me the way you talk about this person's kid? Or like why can't it be like the same level for you? That part sucks I guess... I guess it just impacted me negatively... because I feel like I am not like the ideal Tamil person...

The expectations that are placed upon women frustrate them-whether it was to do well in school, or o uphold the prescribed cultural standards that their parent's have for them. It made them question the authenticity of their Tamil identity when these standards were not met. Ideas of cultural purity have had negative implications on women's self-construction, Diya says:

I was like this golden child, and it didn't take that much out of me, or it seemed like it didn't take that much out of me, but I still compromised a lot because I don't think you are supposed to live that much of your life not being authentic.

Many of these women were not permitted to be authentic to their selves and as a result do not feel they were able to organically grow as a person.

However, not all women share this sentiment, Ranji states that cultural purity is a subjective idea, it depends on the family, and how they approach living in Canada. Similarly, Thenuja expresses that her family has adapted well despite cultural differences. One surprising theme that came out was that many women do appreciate learning about their culture, and even go so far as to stress that they sometimes feel sorry for the men who are not expected to learn about their Tamil culture. Thenuja and Arssana stress that they would like to pass down cultural traditions to their children. Thenuja even states that she does not mind partaking in things her parents enforce on her so she can keep certain things alive. It could be concluded that these women appreciate learning about their culture and that they wish that the men would share the burden of maintaining culture with them. 


\subsubsection{Cultural Taboos}

Other themes that arose concerning trauma were cultural taboos regarding alcoholism, divorce, mental health, sexual abuse, and child molestation. The conversations unfolded beyond the influences it had on women and included the influences it had on men. It continued towards the necessity and importance of creating discourse and dialogue for the betterment of the Tamil Canadian diaspora as a whole. Addressing the entirety of the Tamil community's relationship and reactions toward all cultural taboos may be beyond the scope of this study, however, it is worthy of specific note to touch on alcoholism and mental health as these two themes pertains to ideas of trauma concerning the Civil War.

Mental wellness plays a heavy role in these women's lives. Beiser et al. (2011) argues that the Tamil diaspora in Canada is in grief due to the war and that there is not enough discourse on the ways to help the Tamil community. Research indicates that increased levels of emotive reactions to trauma strengthen the memory of the trauma (Beiser et al., 2011). If there is no outlet to consider how the trauma of the war manifested in people's lives, it can have dire impacts on them. For example, Arssana, who has a background in psychology, says:

[My parents] were pretty silent about it, unless it comes up in like family conversations because my mom had brothers who joined the rebel movements. Uhm, my mom had seen her neighbour and her best friend be blown up when the Indian army was there. So, it's things like that. Like, they don't consider it PTSD [Post Traumatic Stress Disorder] because they do not know those terms, but it's not news they would just be like blabbering and talking about it casually, but it does come out in stories, like she took me to houses that she was raised in she explained like "oh this is where certain stuff was happening."

Throughout our conversation she shares how she believes her mother has anxiety and suffers from PTSD. At one point, she even commented how she was uncomfortable sharing her artwork with her parent's because she was "scared of how it will affect them as well." In this way, she became the protector and acknowledges it does affect her relationship with her mother. She also 
states it is probably due to her psychology background that she notices these things and not because her mother mentions it. In light of this, there was no discussion of whether she urges her mother to seek help.

Another aspect prevalent throughout these conversations is the children's negotiation with their own trauma. Sharan, who asked for therapy as a result of her home life, was not allowed to find a therapist by her parents. When asked why she thought that was, she felt that when it came to their own children asking for therapy, they didn't want to believe it was them who had caused their children's trauma. She says: “it was their own problem, what is happening in Sri Lanka is out of their control, what is happening at home is within their control and that's why they didn't want to talk to us about it, or send us to therapy or be open about it." Her parents did not want to acknowledge their role in contributing towards trauma in their children, and so refused to talk openly about it or find ways to get help. This frustrated Sharan, as she needed guidance when she lived at home and did not know where to get it.

Paternal alcoholism was another theme that surfaced in two interviews. Some of the women were estranged from their fathers as a result of alcoholism, and so it was difficult for them to negotiate their relationship with their parents. Renee shares:

So, I went back a couple of times, the most recent time I went back was last summer... [My mom and dad] experience Sri Lanka in two different ways. Uhm, my dad can get either really emotional and I have seen him... the only time I have seen him cry was in Sri Lanka, and one other time, uhm, because like it's so much... Uh, he can also get... I think when he drinks in Sri Lanka, like when he drinks with his friends and stuff, I can see it is traumatic drinking. It's not like, it's not just for fun, it's very like, "I can't handle the scenario I am in right now, so I have to drink."

She is keenly aware of how her father interacts with others compared to family, and though it is difficult for her and her mother at home, she acknowledges that he is coping with the trauma of having experienced life through the lens of the Civil War. 
Furthermore, coping with trauma through alcoholism can have negative impacts on the family as a whole. Sharan says:

It was a struggle growing up because my dad was an alcoholic and he was abusive, and all those Tamil stereotypes, and I had to live with that for a long time, and it was really toxic... Like, it's hard when you live under a house like that because like you want your mom to do better for herself, but she is also restricted from doing what she wants because of our culture and stuff. I understand why they wanted to stay together, and I knew like... after a while my anger towards my dad decreased because I realized it was a disease and not him. But, it was very hard to separate that person from their disease when it is your own relative.

Sharan was very conscious of how alcoholism can affect a person, but she did not know how to negotiate that when it is her family. When Sharan discusses the feeling that her own mother cannot leave the marriage because of cultural stereotypes against divorce, she elaborates on how women are treated within the community:

We are dismissed and ignored. I don't think people think it's important and I think they think we have to tackle like Tamil issues versus Tamil women's issues first. You know what I mean? Like, if there is an alcoholic problem in the family, it's always like "How is he dealing with it? What can we do to help him?" They never really ask "How are the women in the family doing? How are they dealing with it? Like, should they be..." no, it's always like, "we have to help the man."

She is frustrated by women's lack of voice in larger discussions of pertinent issues. She argues that women are also impacted when men are alcoholics, and it is important to consider women's voices. This point illustrates how intersectionality is needed to consider oppression (Mann, 2012), the impact of alcoholism extends beyond Sharan's father and to the rest of family as well. This is why intersectionality is an important means to dismantle structural oppressions that affect marginalized women (Crenshaw, 1989). In Sharan's view, it is important and necessary for their voices to be heard on issues such as alcoholism and the impact it has had on their lives. It is worthy to note that in the same way alcoholism negatively permeated the household dynamics, it has also negatively impacted the women in particular as well. 
The ways parents negotiate their trauma impacts how children understand their relationship with their parents, as well as what they are willing to share with their parents. Several of these women mentioned their mother's anxiety, which seems to arise more so as a result of their silences and silenced voices than it does as it arises out of the act of sharing their personal narratives and trauma with their children.

\subsection{Identity}

\subsubsection{Identity Conflict}

Another thought that arose from the interviews was the idea of self-hate. Many women did not fully embrace their Tamil identity due to how Tamils were represented in the media and the general reception of Tamil people by the public. Beiser et al. (2011) asserts that in the aftermath of boats arriving in Canada, many Canadians stopped supporting refugees. Coincidentally, after 9/11 the World Tamil Movement was also placed on the national list of terrorist organizations (Beiser et al., 2011). The reception of Tamil people under the assumption of terrorism led many Tamil people to feel undue discrimination directed towards them (Beiser et al., 2011). Many of the interviewed women would also grow to feel and experience these acts of discrimination that challenged their personal identity.

With the exception of Ranji and Thenuja, the rest of the interviewed women claimed they felt ashamed of being Tamil when they were younger. Yet, as they grew older, they also grew to appreciate this aspect of their identity. For example, Theepa, who immigrated when she was seven, was bullied because of her background and did not appreciate her ethnicity. However, she was able to embrace her identity, as she grew older. Arthy shared a similar sentiment of being reluctant to associate with those of the same ethnicity, going as far as to avoid being a part of the Tamil Student Association (TSA) in high school: 
Yeah, even if they are my age or older or younger, they all... we all like have sort of like... I don't know like... this identity... and this is where we came from, almost like, we have all experienced the same thing... Like... in 2009 when like all that was happening we had a TSA... like there's a TSA in all the schools... So I never wanted to be a part of the TSA because I had that like, I didn't want to be Tamil Sri Lankan at that point because everyone is having negative connotations towards it or like that identity. And uhm, because of the lack of the knowledge more so, even I was guilty of that because I didn't actively pursue it to figure out what was happening in Sri Lanka at that time....

Arthy was ashamed of her Tamil identity and did not want to learn about the Civil War.

Simultaneously, Arthy was also aware of how the Canadian community was not educated on what was happening in Sri Lanka. It was only through meeting and talking to other Tamils did Arthy find pride in being Tamil.

These women also never felt fully accepted. They felt like the othered-not fully understood nor accepted by their white counterparts. Arthy states that is often difficult for others to understand or accommodate what the Tamil community is going through, since they are still a recent diaspora, and they are not fully embraced by others. Diya reaffirms this by arguing:

... Uhm, I think it was more work to not be white when you were younger, or when I was younger. When I was in a kindergarten classroom... the things that made me feel different, didn't make me proud. Like, I didn't feel like I can come to a table and be like "guys I am different and there are the things that make me special." It's more like I need to hide everything that makes me different, and be as neutral as people and adapt and pretend I have a seat at this table type of thing. I am just going to hide whatever makes me different, and get on board as fast as possible, so I can catch up to these people's conversations. Even a few years ago, this person was like "oh, this girl has really curly hair like the girl from Grease." And I was like "grease?" and she was like "oh, you've never seen that movie, how could you have never seen that movie?" Like people make you feel you are behind if you are not caught up with mainstream culture, yet I know so many Tamil musicians, and movies, and literature that doesn't seem to count for anything, does that make sense?

In this quote Diya demonstrates how she feels her worth as a person is tied to being familiar with Western culture. Yet, her knowledge of the Tamil community does not amount to anything in conversations with white colleagues, and she almost felt ashamed for not knowing certain 
movies. Diya asserts that she "lacks whiteness" and it almost made her feel like she had to erase a certain part of her identity to fit in. These women shared similar stories of not being able to embrace their identity until they were older, and allowing themselves to learn more about what is happening in Sri Lanka or more about their cultural identity.

\subsubsection{Countering Hate with Cultural Appreciation}

All women found solace in living in the GTA because they all felt that they were truly able to appreciate and grow in their culture and to understand who they were since they were exposed to other Tamil people. Theepa shared: "I love being in Toronto for that reason, because I don't feel like an outsider". She also elaborated that her Tamil friends in university helped her to embrace her identity. By building meaningful connections within their communities, these Tamil women found significance within their own identity. Renee affirms: "I love my Tamil friends to death" since they helped her to overcome traumas in her life, while Arthy asserts her Tamil friends are easier to connect to because of similar backgrounds. The ability to have people that share the same cultural background allowed these women to find importance within themselves. Simpson (2011) asserts that communities can generate meaning; and as these women built relationships within their community, they were able to produce knowledge and generate meaning for themselves.

Arthy shares that she was able to embrace her hybrid identity, finding a happy medium between being Tamil and being Canadian, because of her friends. She had the support of her friends in embracing her individuality, which alleviated the pressure of trying to maintain a separate identity between being either Tamil or being Canadian:

I think it was like... I saw what my friends were doing, like being more carefree, and not like having all these pressures of maintaining a Tamil culture that I felt like I had to go back... like basically throw away my ideals or Tamil culture or cultural purity... Like, it was more like I found it wasn't just me that was feeling this way, I felt like I found 
people that were going through the same thing, but like they found a balance they were able to come to terms with it, and that helped me come to terms with it because they went through the same thing. And now like I kind of like I am in a way better place than I was before, like I can be a fully functional Tamil Canadian... like, keeping that culture alive and keeping all those morals alive, and have those traditional values in check.

She was able to bring both her identities together because she had supportive friends. By embracing each other and their individual identities, she and her group of friends were able to disrupt the influence media discourse had on her with regards to Tamil people. It was important for Arthy to find this group of friends and find a space for her to function, so she can understand her individualized hybrid identity

All these women shared experiences on conforming to a certain ideal of being separately either Tamil or Western, however, through supportive interactions with their friends and being surrounded by Tamil people, these women have found ways to understand and come to terms with their own identity. These relationships have allowed them to realize that they are not solely either just Tamil or just Canadian, but that they are able to exist as a hybrid identity. This underlying theme of having a fluid hybridized identity ultimately manifests itself in their art, which will be explored below.

\subsubsection{Women's Role in the Tamil-Canadian Diaspora}

The women interviewed expressed frustration concerning their role defined as reproducers or as how people in the community perceived them. In the role of reproducers, the disconnect between genders with regards to expectations in upholding cultural purity proved frustrating, as male counterparts were more readily permitted to date outside of their culture, whereas women were not. Bhatia and Ram (2004) assert that dating outsiders is frowned upon in South Asian communities, and it is considered to be an act of weakening the culture. Bhatia and 
Ram (2004) continue to elaborate that women uphold most of the burden of dating and reproducing within the culture Diya shared her frustration in having to uphold these ideals:

... I don't see men having that pressure at all and even if they deviated from that... they get away from... it's like... "Oh, my son can have an interracial relationship" for example, but the woman should probably find a Tamil man.

Sharan shared that she was not attracted to Tamil men, and that it took her some time to convince her parents to accept her interracial relationship. She expresses the frustration that within the Tamil community, men do not respect the idea that she is with a black man and consistently questions the reason she is with him. However, her male cousin counterparts have been able to date women of different ethnicities without having received as much resistance. These women were frustrated that these choices were actively taken away from them because of their expectations to date within their culture.

Women also expressed frustrations that they have been reduced to the sole task of bearing and raising children. Theepa and Arthy both expressed the desire to choose to have children. Despite being born a decade apart, they both share the same frustration. Theepa shares:

What frustrates me is because I'm a female I- I have a time limit. And those are already self-imposed on myself because of biology... I understand it, but I don't want other people putting that on me because it's more stressful than it needs to be, right? And I think- I don't like that. So I have a hard time with that, and my parents always asking me "When are you going to have kids?", and "Your clock is ticking, we are going to die" and it's like okay...

Theepa's parents' expectations seem to stem from the fact that none of her siblings are married; resulting in increased pressure for her to reproduce. Arthy also expressed frustrations about being pushed into marriage so young - she reiterates that her older male cousins are not pressured this much:

Like, it is confusing to me because in that case you should probably tell my male cousin to get married because he is older than me, because they are associating this with my age. Like, they think we can't have kids after 30 or something, but I am like "Technology has 
advanced in that sense!" But to them that is still taboo... or people will start talking in a certain way... like, "Why is she having kids so late?" ... Like, I don't understand that at all... maybe it's because of like this mentality that they don't think that older women can have healthy children. I mean yeah, scientifically, yeah, the risk increases, but I don't think it should literally like, you should base your decision to get married solely on that... as women to procreate. Like, that should not be the reason that I am getting married... Like to grant you grandchildren, like no.

Five of the eight women expressed feeling suffocated by the notion of needing to have accomplished specific milestones by certain age-related deadlines. These milestones defined for example, when to have graduated from school, when to be married, and when to have children.

These women want to be seen beyond culturally defined roles and milestones - instead, it is their desire to be viewed as autonomous beings capable of making their own decisions.

Each of the women expressed disappointment with the position of women within the Tamil community. They felt overtly objectified through the prevalent hypersexualisation of their own bodies - often aggravated by the male gaze. Most of these women express their desire to be viewed as a multidimensional person-instead, they often feel like they need to conform to certain behaviours in order to feel safe. Arssana elaborates on this feeling, and describes how her art aims to tackle these issues:

...I would like to dress however I want to be and a lot of my art actually talks about the hypersexualisation of women's bodies. So, I think even if I feel a need to barely wear anything, I should feel comfortable enough without the male gaze, or anybody's gaze making me uncomfortable, because I shouldn't be sexualized for any reason.

These women would like to be viewed as more than what they what they wear, to be perceived as how they are as a person and not a sexually objectified being. Theepa shares that her photography has allowed her to observe the behaviours of men around women more deeply:

I would just notice things at events and parties because I am a wedding photographer, I would notice- I look through people from really far through my camera lens, and I would notice people like women, wearing clothes that show their bellies, or breasts, or the sides of their hips, and I would remember men creepily looking at them. And I can see it, they can't see it, they can't see I am looking for them, and my disgust formed and so I would 
never go to an event with anything that revealed any part of me, because I just felt I was being violated.

Theepa felt violated by the male gaze at her commissioned events, despite it not being directed at her. She and the other women echo the sentiment of feeling frustrated by how much they are judged through the clothes that they wear. Sharan argues that often people assume that a woman is better based on how modestly she is dressed: "Like, if I wear revealing clothing does that make me a garbage woman? Like no, you can wear a saree and a pottu with three lines of viboothi, and you can still be the biggest bitch that everyone has met." Due to these perceptions of Tamil women, Sharan aims to reclaim the female body from sexual objectification and judgment through her artwork.

Another grievance women shared was the role their skin colour played on their selfworth. In the present day, South Asian women continue to battle binaries and the implications it has on their identity. These women are marginalized based on an Eurocentric model of beauty, where the pigment of one's skin color determines whether they are perceived as both beautiful and ugly (Bhatia \& Ram, 2004). South Asian women are perceived as ugly based on skin colour, but also beautiful because they are exotic (Bhatia \& Ram, 2004). The interviewed women often experienced the described marginalization and discrimination as a result of being darker skinned-much of which permeated various aspects of their lives and careers. For example, Thenuja talked about how being darker skinned impacted the work that was available to her in her modeling career. Renee talked about how having darker skin exacerbated the already prevalent feeling of negative self-beauty as described by Eurocentric definitions of beauty: "I hated being dark, I hated the frizzy hair, I hated a lot of the beauty standards I didn't live up to." Interestingly, in spite of these perceived disadvantages of being darker skinned, Ranji expressed feeling a sense of disconnect to her culture as a result of being lighter skinned - people often did 
not believe her when she claimed to be Tamil. In light of these initially negative feelings of selfbeauty, these women have grown to embrace the color of their skin. Sharan uses her platform as a darker skinned model to speak out against intolerant notions of beauty and to empower women to reclaim their bodies for themselves. She shares that people have reacted to her work in positive ways: “Oh, she's dark skin and she's pulling that off, also she's a woman and wearing that, also you are Tamil? How are you Tamil and wearing all this?" Her art has allowed her to understand and push boundaries of what it means to be a Tamil woman.

The underlying frustration is there is too much emphasis placed on how women look. The focus on their bodies exasperates them, as they feel they are not taken seriously. They would like to be seen as multifaceted people and for their accomplishments to be taken into consideration.

\subsubsection{Women's Rights in the Tamil-Canadian Diaspora}

Each of the interviewed women expressed frustration on the absence of women's autonomy within the Tamil community, and how it is rarely spoken about. In diaspora communities, gender is often something that is ignored (Hua, 2005). Diya states: "We are just on the sidelines, while men are making their mark, and doing their stupid shit, right? We are the Banquet hall girls, and we are like 'do you want mango shakes?'” Her comment illustrates how women are allowed to observe, but not to speak up. They are on the sidelines serving men, not giving input. Sharan echoes this sentiment:

...We are never talked about. Nobody ever stands up for us, it is not really our community's fault, and it's really like our structure's fault. Women were never told "you have a voice, and you are important, and you are educated"... even if we were educated we were told to keep quiet. Even if we go to school at three universities, and have five degrees we will never be told, "Oh, you should listen to her" or "What do you think about this?" it's always like, you will find the guy in the circle and ask about his opinions and what his ideas are, and always put the man over the women every single time and women have no place in the Tamil community, and ... and when we do finally put a voice out there, people want to bring you down or want to yell at you, or they think you are a rebel in front of everybody when you are just trying to have an opinion, or you're angry or 
have a temper tantrum.

They are frustrated in how their opinions are ignored. It feels as if women are not respected despite being more qualified or equally as qualified as men. Sharan's feelings illustrate the importance of intersectionality - that there is not a single isolated problem that pinpoints the marginalization Tamil women face, but a larger systemic injustice that occurs on a multidimensional basis.

In light of the progressive advancement of certain areas within the Tamil Canadian community, women's issues have largely been overlooked and ignored. As demonstrated by Arthy:

One area that is seriously lacking, where the Tamil community has progressed in every other aspect, like whether it's like focusing on career advancement, or music and the arts, or sports... like, there are like so many positive things happening when it comes to that. But, when it comes to gender, they are so fixated on girls can do this, and guys can do this only and females get the lower end of the freedom.

By not adhering to these gender roles, men and women may be able to accomplish more in the grand scheme of things. Furthermore, this attachment to gender roles can be viewed as resistance to assimilating by previously migrant and marginalized communities. There is a desire to assert difference in marginalized communities from dominant discourse (Naber, 2011). For example, Arthy shares that men are often prohibited from pursuing Bharatanatyam, and conversely, women similarly restricted from pursuing Miruthangam classes due to their traditionally gender specific traditions. These gender roles interfere with the potential for the Tamil community to fully express themselves through creative outlets.

These women are asking for a change within the Tamil community and desire allies in this pursuit. They feel other women are taking on the burden to push for change, without much help from the men in their community. In light of this, Arssana remains hopeful that the narrative 
will shift for the better as women become more empowered and gather the momentum to change not only themselves, but their community as well:

...It will be in a better position in ten years maybe, when a lot of these women have the space to get something out of this, uhm momentum. I do think Tamil men have dominated the scene for far too long, but, I have had some refreshing conversations with like some of those men as well... and they are like, I wish more women would come. That being said, I don't know how receptive they would be if a woman truly [takes on leadership roles]... yeah...

These women all express frustration that their voices are not being heard enough. Renee also expresses the importance of conversations and dialogue being started on the issues women face, and how people need to work together within the community to change things.

\section{$6.3 \mathrm{Art}$}

\subsubsection{Building Relationships Through Art}

These women were able to build meaningful relationships through their art and were able to meet other Tamil women who allowed them to embrace their identity. Ranji and Arthy met other young artists that pursued traditional art forms, and this was crucial in helping them to understand their own background. In some cases, it was extremely helpful for women who would have otherwise found it really difficult to find other Tamil women to connect to since they felt they were too different. For example, Sharan says:

How did my art help me? ... I think it just really helped me first of all, connect with more Tamil people, since I never had Tamil friends like that growing up, like that many. So, now that I have connected with so many girls, who are just like me... like tattoos, I smoke, and like I do this and whatever, so it's really cool to meet other people that are exactly like you and think there are more of me out there, instead of feeling like almost like an outsider. I think the only reason I didn't have many Tamil friends is because they didn't like how I thought or like whatever it was growing up. So, I feel like now that I have done this with my art, I have kind of found my identity and kind of understood that it's okay, you can be Tamil and have tattoos, like dress the way you want to dress, it doesn't make you less of a Tamil woman than the next woman who wears a saree, and goes to the temple or church, everyday. It's just that, I feel like that has really helped connecting with other people through this art form, for sure. I think connecting with people helps you find your identity, for sure. 
In this way, her art allowed her to simultaneously come to peace with her own identity and meet people that are similar to her. It allowed her to move beyond a constructed idea of a Tamil person, and find a Tamil identity that she is able to understand and embrace.

Those who have experienced intergenerational trauma can use art as a means to reconcile their tensions. Hirsch's (2012b) - exploration of postmemory considers how through fragmentations in historical accounts of trauma, second-generation recipients of trauma seek to reconcile their own tensions with the past. The second generation explores how to complete collective memories by reconstructing memories through familial accounts by way of "aesthetic representation" (Hirsch, 2012, p. 33). In their attempt to understand their parents' cultural trauma, children of survivors often use "art, memoir and, trauma" to come to terms with their parents' suffering (Hirsch, 2012b, p. 34). It is in this way that the artistic work survivors' children create may also be used to understand the complexities within their own lives.

Art becomes an important platform in which children can connect to their parents and facilitate discussion based on differences. Though some parents were silent about their experience of the war, they were able to bond through their art. Arthy shares:

It is something that brings us together ... if it was a regular day I would just go up to my room and not talk to my parents really, you know what I mean. There is something to discuss with my parents because they are also interested in it. We all have this common topic to talk about, and it can be anything from like, what cover we are thinking to do, cause we like their opinions...

In this case, art becomes a bridging tool as a means to connect between generations. It allows children to reclaim a relationship that otherwise might have been lost. These parents have inspired their children and how their children choose to pursue art. For example, Theepa was inspired by her mother's love of fashion and drawing - she recalls her mother's wardrobe in Sri Lanka, which they had to leave behind when fleeing the war, as something that was artistically captivating and 
this inspiration ultimately led her to start a fashion blog. Similarly, Arssana shares a moment of bonding through painting with her mother:

She's like my biggest fan of my artwork, she is very supportive. And sometimes I will be painting, and she [will want] to outshine me as an artist... so she bought canvases, and sat there, and painted with me... [laughs] And she'll go around and be like "Arssana made this," and when people believe her, she'll be happy because she did it. So that's what she does. I think it does build, like, it is a bonding experience and I am grateful for that.

These women found ways to bond ways through their art form. However, Diya's mother stood out as an example of when art was not able to bridge the gap between generations as she did not react positively to Diya's art, who explains that how her mother reacts to her artwork is traumatizing for her and she learned to disengage from her mother's reactions. Ultimately however, the women interviewed affirm that art was often a cathartic expression that helped them to understand themselves, their parents, and their shared collective history.

\subsubsection{Awareness, Resistance, and Resilience}

The women all stressed the importance of using art as a means of awareness, resistance, or resilience and tackled many issues through their art. Artists like Ranji were keen on bringing awareness of the atrocities that happened in Sri Lanka through dancing, there were other artists like Theepa and Arssana who used their photography to battle the sexualisation of women's bodies and Thenuja uses it as a means to stay in touch with her Tamil identity. Through these discussions with women it was understood they used art as a meant to negotiate their grievances, and produce a tangible and visual piece of their traumas or frustrations.

Papastergiadis (2005) states that there is a need for different mechanisms to be developed for understanding and making sense of different cultures and languages. Thus, art can be a necessary platform for diaspora members to be heard, and especially essential for women who are overlooked. Ranji states: 
... I see my art as a form of awareness, and I would say I see my art as a form of awareness and acceptance. Acceptance of my Identity, my Tamil culture, my Canadian culture, but also as a form of awareness, of my culture to the foreign audience. And I also see it as a form of... a form of... healing...

Her art is a platform that she feels her Canadian audience is willing to accept and digest, because almost everyone is willing to engage in and enjoy art.

Some women even stress art as something that is bigger than themselves and is essential to bringing awareness on topics that are difficult to understand. Bhimani (2006) states "The space that lies at the intersection of artist, activist and academic is a powerful place, as it can be the womb where knowledge, invention and action give birth to mechanisms that allow movement towards the enhancement of humanity" (p. 90). Their art has become an important site to start discourse and to engage in discussion, and allows them to carve out a space to be activists and to share the ideas. Sharan shares when asked about how art is necessary in the Tamil community:

So, I feel like we are all using art as a safety net to talk about it versus going out in public and like saying all this stuff, because it not only attracts people's attention in a good way, but also, we can explain ourselves without being interrupted, like art is the only thing people cannot interrupt, if you think about it. It's the one thing people can't tell you to shut up, it's the one thing people can't be like you should say less, don't talk too much, you're going to scare away a guy, or whatever. It's the one thing that just stands out without you having to say as much.

All women share the general idea that their art gives them a platform that forces people to listen, and allows them to be heard. Furthermore, on the work they create themselves, these women are extremely proud that they can engage in conversations that maybe the Tamil community may not be willing to accept. It gives them a tangible means to be strong. When asked if her art is a form of resistance, Arssana states:

One, being an artist itself is somewhat resistance in a community that favours jobs like lawyers, doctors, engineers as careers. I think being a woman is resistance on its own, but also the types of things I engage in, like my art, isn't ashamed of nudity, isn't ashamed of sexuality, isn't ashamed of a lot of things we are very hush hush about. So I think that is resistance, and I think it takes resilience to push those boundaries as well. 
Furthermore, all these women shared the idea that through their art they can be seen as women with agency. When asked if her art is seen as a form or resilience, Arthy claims:

To break stigma almost? I definitely think that is true with me at least because with this art form, there is an image of it that it is very feminine it is very sacred.... the veena at a heart of it is an instrument, and it is a way to express yourself and your personality and it is not just a generic Tamil girl like playing the veena. Like I have this personality, I like these sounds, I like this kind of music

To Arthy, despite choosing a traditional instrument, she contends that she is so much more than the instrument and what it represents. She is reclaiming agency by redefining the kind of imagery a woman playing the veena evokes - she wants people to think beyond her instrument, and to also consider the woman that is playing it.

All these women felt like they were reclaiming agency through their art, and trying to have their voices heard in the Tamil and Canadian community. These women have important stories to be heard, and in some sense art has become a healing mechanism. Diya states about the role her art plays in her life:

I feel like I am reclaiming something, I feel like as a Tamil woman we have been reduced to something so much smaller than we actually are, yeah... like just the state of the world, the way we are being paid, the way we are being treated, the way we are being displayed in movies, it's so different from who we actually are.

Their art becomes a mean to negotiate their identity and to reclaim agency and it has become a way to reclaim a narrative that people have imposed on women. Through their art, they have overcome ideas of passivity imposed by both Western and Eastern constructions since they are producing, creating their own stories, generating knowledge and most importantly they are redefining their culture.

\subsubsection{Tamil-Canadian Women's Hybrid Identity in Art}

Art can be a means to fuse two identities, and to negotiate ideas of self-construction. In 
terms of hybridity, it is necessary to think of how there is an ongoing dialogue between two cultures (Hall, 1994; Papastergiadis, 2005). Furthermore, Art extends beyond borders, and redefines boundaries of the nation (Bastos, 2006). Thus, these women who have been inspired by Tamil and Canadian identity are creating a dialogue between two identities. Papastergiadis (2005) argues that art created by diaspora can "be a production of knowledge about the other and a frame of experience of everyday life" (p. 41). In this sense, art can be an enmeshment of two cultures, and negotiating a diaspora subjects grievances within the two communities they live in.

All of the girls have talked about how they fuse their art both ways to understand and negotiate ideas of themselves and their identity. For example, Ranji danced to a classical dance to the Game of Throne theme song, however she was very careful to remain true to the traditional aspect of the music.

I strongly believe you have to stick to your core fundamentals of Bharatanatyam, for example...but me personally, having learned the traditional art form, I can be doing Game of Thrones, but you will never see me wear shoes and dance Bharatanatyam, because I feel like certain aspects is respect for the actual art form. Like, for one of my covers, it's on YouTube and Instagram, I literally danced in the snow, I did a cover in the snow, outdoors, while it was snowing like crazy, and even then in like the negative degrees, I did not wear shoes, because it is respect for the culture because Bharatanatyam has strong ties to Hinduism, and when we dance we believe that God is everywhere, so the ground it is called Bhooma Devi, so it's that respect. So basically when we dance it's our connection with the ground, with Mother Nature while we dance. So because of that, even though we go beyond measures... for example, like Game of Thrones, I am bringing like a Western idea and I am kind of changing it around to blends the traditional and modern together, so it's like a modern classical. But even then I still ... I wanted to stay true to it's culture and traditions, like no shoes. Like, even when I am dancing, I am not changing my fingers or ...my postures all Bharatanatyam it is just moving to a different music.

Her art gave her a mechanism to explore her identity as a Canadian and Tamil woman, who wants to embrace both identities and finds creative means to fuse these two cultures together, for example by dancing Bharatanatyam in the snow.

By allowing two identities to create a dialogue between each other, women also find 
easier ways to overcome their trauma. Between the conversation Renee and I had, I was able to understand how that the Tamil art community was essential to her well being, she asserted that her Canadian art friends was always asking her to unearth her trauma, and expose herself more, however she was unable to. Simultaneously, they also aimed to make things more aesthetically pleasing than Renee desired. In our conversation she stated:

I think the Canadian arts community always trying to make things artistic and beautiful and very Tumblry and Tamil people are so not... [Like more raw?] We're very raw, yeah.... So, I try to remain raw and not make things so flowery.

The entanglement of these two identities have allowed her to find a happy medium between her cultures, and to explore her poetry through themes of trauma that does not leave her paralyzed.

Moreover, these women are careful to respect their culture in surprisingly different ways. For example, when asked how she feels about how her community may perceive her modeling Thenuja states:

If I am going to do a shoot I always ask questions about what kind of look we are going for, or what the mood is... I don't want to have to like disrespect our culture, or our identity, or anyone in particular. Uhm, you know obviously you have to be prepared with what kind of comments you get and try to minimize that...

She is careful to accept certain modelling jobs. However, she is sometimes surprised by the community's reception of her work. For one magazine, she did a more creative shoot where she was not just modelling sarees. She said "uhm, it was like there was one outfit, more like the clothes that you will wear with Bharatanatyam, mixed with a skirt and that's where I got a little scared, because obviously dancers will be a little disrespected, but a lot of people really liked that outfit." She was surprised by the Tamil community's reception to her outfit, as Bharatanatyam clothes are often very traditional, however, this exemplifies how art can be a way for women to weave two cultures together, and people can see how identities do not have to be entirely Canadian or Tamil, and they can be fused. In some ways, Thenuja's clothes are helping to 
facilitate acceptance of hybridized identity for the older generation and allow them to understand the coming together of two identities on a visual level.

Some girls even used it as a means to critique Tamil identity and to understand their own grievances with their community. When asked if her hyphenated identities affect her work Arssana stated:

I don't know if it affects my work on like a conscious level, I think it affects my work on a subconscious level because exploring the hyphenated identity has been something I have always done... I think in a lot of my raw artwork, it does come out, but I don't start a painting saying like "hey I am going to talk about my mixed identity here." But, it has come out, like I made a piece... with Lord Krishna, and uhm his mom carrying him, but I splattered white paint over him as well, just to uhm explain that often God gets hidden in the name of religion, and that was my critique on...the patriarchal cultural interpretation of Hinduism, and that was my way of expressing it, but I didn't start the painting like saying like, "this is my intention," it just kind of became like that.

Though she does not always start out her art pieces with the intention of fusing the two, it turned out to be a means for her to understand what she feels is wrong with a certain aspect of her culture or religion. It gives her a physical means to understand her feelings.

For these women, art has become an important means for self-construction. Most of the women responded by saying how traditional art forms, such as the Veena or Bharatanatyam, has allowed women to stay in touch with their Tamil identity, especially through the theory class that the women have to take. However, for other women, it also became a source of self-enquiry. Diya, when asked how her Tamil and Canadian identity influences her work, states:

I can't, like, separate those identities, and the work actually is to help clarify to myself what are these identities, and how does that play out through me. I... I am Tamil, but I am not Tamil in the way my mom is Tamil, or my grandma is Tamil. Uhm, and I am not Tamil in the way my sister is Tamil, because she has had somewhat of a different experience from me like taking Women and Gender studies or whatever. So the how, uhm... I guess it is me exploring and figuring it out, rather than knowing and expressing. 
She acknowledges that she cannot make a separation between her Tamil or Canadian identities.

In this case, the hyphen is important, her Tamil-Canadian identities influences and gives

meaning to her work. When asked to explain further she states:

Something that comes to mind is this project I did. It's like this woman on the ground, and a foot on top of her... or like someone's foot on top of her head, and he's wearing a saram with like Sri Lanka written on it... I think that one was about being a Tamil woman, and growing up in a family where domestic abuse is an everyday thing, and uhm... I guess like the Canadian part of that picture, or most of my photos, is the fact that I get to be an adult artist who has access to these resources, and I am living now in 2017 with things like Instagram or the internet where I can share it, that's is my Canadian experience. Even with like the war and stuff, it was really horrible that happened, but it was like a weird twist of fate, for like my ancestry, because now I am here across these oceans, and no one in my family has ever been able to do that before...if I was back there I don't think I could own a camera.

She acknowledges how her life at home influences her artwork, but her being Canadian, and having access to technology and equipment has allowed her to be the kind of artist she wants to be. She recognizes her privileges in being in Canada, and how even being a photographer is as a result of being Canadian.

These women all acknowledge the symbiotic relationship both their identities have-they cannot exist as an artist without her Tamil or Canadian identity, and it is essential to their work and their personhood. Moreover, the experiences they have encountered have inspired them to produce art that is essential in changing the discourse around Tamil women, as they feel both the Tamil and Canadian community are receptive to their art. 


\section{Conclusion}

"we all move forward when

we recognize how resilient and striking the women

around us are"

-rupi kaur, milk and honey, 2014, p. 177

The women in this study were able to negotiate their inherited experiences of the Civil War through the use of art. Ranji shares how she was able to mediate her ache to go home, Sri Lanka, by dancing. Art became a means to overcome and negotiate her melancholy. Additionally, despite sharing trauma with other community members, these women have a medium to release that trauma and connect to parents that they otherwise may have difficulty talking to. These art forms have become important sites of negotiating trauma and identity. Women's hybrid identities were able to come through their artwork, and many women found they were thankful that they have these opportunities to pursue art.

This study indicates that diasporic Tamil women's strong attachment to their culture. Some women emphasized the need to preserve the stories their parents and the older generation carry with them, these stories are essential for younger children to negotiate and understand their identities. Thus, despite popular assumption that immigrant women are trying to move away from their Tamil identity, they are trying to find creative mechanisms to preserve pieces of culture for future generations to embrace.

It is evident that for young Tamil women, art is an important mode of communication with their own community as well as the Canadian community. Often Tamil women's voices or their frustrations are ignored because there is an emphasis to preserve a form of identity the Tamil community is afraid they will lose. Women have been able to use art as a mechanism to have their voices or heard. 
It is important to consider this project focused on emphasizing the significance of Tamil women's voices and women's autonomy, particularly how they reclaimed space and voice within their community through art. This study offers some insight into the ways in which young Tamil women seek to disrupt and claim space for themselves within the larger Canadian society. In thinking of future projects, it is necessary to consider the construction of young Tamil women within the larger Canadian landscape and culture where unique spaces are assigned to communities and individuals on the basis of race, gender, class, sexual orientation, dis/abilities and so on.

Art can also be used to start dialogue around frustrations women have. For example, Theepa recently took part in a photo-shoot for a popular Tamil-Canadian bridal magazine and she opted to pose the Tamil model on the cover with a long slit running across her saree, and her leg was showing. Theepa's choice to pose the women was as a result of the frustration of the sexualization of the women's body and she wanted the Tamil community to engage in conversations about this. Theepa received a lot of backlash from women and men in the Tamil community alike, she even shared that an older woman had sent her a message on Facebook saying, "you should be ashamed of yourself."

Recently, I attended a party and the conversation turned to this magazine cover, in which the women commented that they understood why Theepa posed the women the way she did, however they believed she should not have used a bride. They felt that a bride should remain traditional, and her modesty should not be tarnished. Furthermore, a man also commented, "she did it for publicity." In hearing these conversations, I was taken aback, and commented she must have done it because she wanted to disrupt people's thoughts and start a conversation, and he became more insistent that it was a publicity stunt. It made me wonder why people are so quick 
to invalidate Tamil women's work, and to assume a woman, who is a highly sought after photographer, and already has an established name within the wedding industry, would use this cover with the main goal to garner recognition. It also made me wonder why no one in this conversation would consider why it was essential for her to use this platform to disrupt people's thought, and have her thoughts on the sexualization of women's body heard.

Respect for women's work is a necessary and important thing to consider for the betterment of the Tamil community. All these participants were able to generate important and necessary discussion about their work, whether it is about domestic abuse, sexualization, or the Civil War in Sri Lanka. Furthermore, these women were able to find solace in their artwork. Theepa in her bridal magazine used a darker Tamil model, which was important and necessary to see, as lighter skin is celebrated within the Tamil community and also disrupts Eurocentric notions of female beauty. She was able to start necessary discourse of women's bodies and how she chooses to dress. Her work was subversive-the magazine cover itself was a visual shock to many people in the diaspora, based on comments on Facebook and Instagram, and it forced people, women and men alike, to rethink, if not to renegotiate, what they understood about Tamil women. This is why it is essential for women to produce this work, as Sharan claims "art is the only thing people cannot interrupt." It allows women agency, and to be able to reclaim their voice. 


\section{Appendix: Interview Guide}

\section{Biographical:}

1.) What is your name?

2.) How old are you?

3.) What religion do you practice?

4.) How many siblings do you have?

5.) Were you born here?

6.) If not, how old were you when you came to Canada?

\section{Work:}

1.) Did your parents enrol you in a traditional art form?

2.) What kind of art form do you gravitate towards now?

3.) Do your different identities - Tamil and Canadian — affect your work? Can you explain the relationship between art and your identity?

4.) Do you discuss your art with your parents? What happens when you talk about your art with them?

\section{Relationships with Family:}

1.) Describe your home life.

2.) How do you see your relationship with your parents?

3.) Do you speak Tamil and do you think it influences how you get along with your parents?

4.) Who did you find yourself closer to growing up, your mom or dad? Why? How about now?

5.) How do you navigate your relationship with your parents?

6.) Did your parents have certain expectations for you growing up that you had difficulty understanding?

7.) Do you feel the way you behave is more a reflection of your mother or father, and how does that make you feel?

\section{Memory:}

1.) How did your parents talk to you about the War in Sri Lanka? What did they say?

2.) Do you remember how you learned about the war, and how you felt?

3.) How did their silences or openness affect you?

4.) Do you remember feeling affected by the way your parents navigated these memories/trauma?

5.) Did you ever feel your parents were concerned about your memories attached to Sri Lanka? What did they do to make you think so?

\section{Diaspora Communities:}

1.) Do you feel you are a part of a strong Tamil community in Toronto?

2.) How do you feel women's issues are represented in the Tamil Canadian community? 
3.) Do you think collectively the Tamil community believes in cultural purity?

4.) Do you feel women bear the burden of remaining culturally pure? If so, how?

a.) What are your own personal experiences with this?

5.) How do you think second-generation women navigate these expectations from their parents?

\section{Identity:}

1.) Do you have difficulty maintaining your parents' expectations for you?

a.) How did this affect how you viewed yourself?

2.) If you felt there was a need to maintain cultural purity, did it affect your identity?

3.) How did you balance your identity at home and the public realm?

4.) How did you share personal problems with people? Was there a difference in how you spoke about it with your friends, parents, or teachers?

5.) As a young person, did you feel like you were navigating two identities? How did that change now?

\section{Work:}

1.) Describe the role played by your art in your relationship with your communitiesCanadian and Tamil?

a.) What is the role of your art in you self-construction (identity)?

b.) Do you see your art as a form of resilience or resistance?

2.) Can art help or hinder younger Tamil women find a place within the Canadian-Tamil women? 


\section{References}

Agnew, V. (2005). Introduction. In Diaspora, Memory and Identity: A Search for Home.

(p. 3-17). Toronto: University of Toronto Press Incorporated.

Akman, H. (2014). Art as Political Expression in Diaspora . In H. Akman (Ed.), Negotiating Identity in Scandinavia: Women, Migration, and the Diaspora(pp. 15-30). New York, NY: Berghahn Books.

Alexander, J. (2004). Toward a Theory of Cultural Trauma. In J. Alexander (Ed.), Cultural Trauma and Collective Identity (pp. 1-31). Berkeley, California: University of California Press.

Alison, M. (2003). Cogs in the Wheel? Women in the Liberation Tigers of Tamil Eelam. Civil Wars, 6(4). 37-54.

Alshenqeeti, H. (2014). Interviewing as a Data Collection Method: A Critical Review. English Linguistics Research,3 (1), 39-45.

Amarasingam, A. (2015). Pain, Pride, and Politics: Social Movement Activism and the Sri Lankan Tamil Diaspora in Canada. Athens, Georgia: University of Georgia Press.

Anthias, F., \& Yuval-Davis, N. (1989). Introduction. In N. Yuval-Davis \& F. Anthias (Eds.), Women-Nation-State(pp. 1-15). Hampshire, England: Macmillan Press Ltd.

Anzaldúa, G. (1981). Speaking in Tongues: A letter to 3rd World Women Writers In This Bridge Called my Back: Writings by Radical Women of Colour. (p. 165-174). New York: Routledge.

Atkinson, R., \& Flint, J. (2001). Sampling, snowball: accessing hidden and hard-to-reach populations (N. Gilbert, Ed.). Social Research UPDATE,(33), 1-4. 
Axel, B. K. (2002). The Diasporic Imaginary. Public Culture,14(2), 411-428.

Bastos, F. (2006). “Tupy, or Not Tupy?: Examining Hybridity in Contemporary Brazilian Art Studies in Art Education, 47(2). 102-117.

Beiser, M., Simich, L., Pandalangat, N., Nowakowski, M., \& Tian, F. (2011). Stresses of Passage, Balms of Resettlement, and Posttraumatic Stress Disorder among Sri Lankan Tamils in Canada. The Canadian Journal of Psychiatry, 56(6), 333-340.

Ben-Rafael, E. (2013). Diaspora . SAGE Journals ,61(5-6), 842-861.

Bhatia, S., \& Ram, A. (2004). Culture, Hybridity, and the Dialogical Self: Cases From the South Asian Diaspora. Mind, Culture, and Activity,11(3), 224-240.

Bhimani, S. (2006). Reconstructing Our Culture of Ilm (Knowledge): Muslim Women Present Themselves. In D. Brandt (Ed.), Wild Fire: Art as Activism (p. 89-98). Toronto, Ont.: Sumach Press.

Bissett, J. (2008, May). Security Threats in Immigration and Refugee Policies (A. Moens \& M. Collacott, Eds.). Immigration Policy and the Terrorist Threat in Canada and the United States, 75-94.

Bradimore, A., \& Bauder, H. (2011). Mystery Ship and Risky Boat People: Tamil Refugee Migration in the Newsprint Media. Canadian Journal of Communication, 36(4), 637-661.

Brinkmann, S. (2014). Unstructured and Semi-Structured Interviewing . In P. Leavy (Ed.), The Oxford Handbook of Qualitative Research(pp. 277-299). New York, NY: Oxford University Press.

Cheran, R. (2007). Citizens of Many Worlds:Theorizing Tamil DiasporiCity (R. Cheran, D. Ambalavanar, \& C. Kanaganayakam, Eds.). In History and Imagination: Tamil Culture 
in the Global Context(pp. 150-168). Toronto, Ont: Coach House Printing.

Cohen, N., \& Arieli, T. (2011). Field research in conflict environments: Methodological challenges and snowball sampling. Journal of Peace Research,48(4), 423-435.

Cixous, H. (1976). The Laugh of the Medusa (K. Cohen \& P. Cohen, Trans.). Signs, 1(4), 875-893.

Crenshaw, K. (1989). Demarginalizing the Intersection of Race and Sex: A Black Feminist Critique of Antidiscrimination Doctrine, Feminist Theory and Antiracist Politics. University of Chicago Legal Forum, 1989(1), 139-167.

Doucet, A. (2007). "From Her Side of the Gossamer Wall(s)": Reflexivity and Relational Knowing. Qualitative Sociology,31(1), 73-87.

Dunlop, R. (2015). Memoirs of a Sirdar's Daughter in Canada: Hybridity and Writing Home. In V. Agnew (Ed.), Diaspora, Memory, and Identity: A Search For Home (pp. 115-150). Toronto, Ont.: University of Toronto Press Incorporated.

Edkins, J. (2003). Introduction: trauma, violence and political community. In Trauma and the Memory of Politics (pp. 1-16). New York, NY: Cambridge University Press.

Fanon, F. (1967). The Fact of Blackness. In Black Skin, White Masks(pp. 109-140). New York, NY: Grove Press.

Finney, S. D. (2014). Under the Shadow of Empire: Indigenous Girls' Presencing as Decolonizing Force. Girlhood Studies, 7(1), 8-26.

Fleras, A. (2015a). Canada's refugee status determination process: controversies, changes. In Immigration Canada: Evolving Realities and Emerging Challenges in a Postnational World (pp. 157-199). British Columbia, ON: UBC Press.

Fleras, A. (2015b). Who got in? who gets in? Continuity and change in Canada's immigration 
Program. In Immigration Canada: Evolving Realities and Emerging Challenges in a Postnational World (pp. 76-118). British Columbia, ON: UBC Press.

George, M. (2013). Sri Lankan Tamil refugee experiences: A qualitative analysis. International Journal of Culture and Mental Health, 6(3), 170-182.

Hall, S. (1994). Cultural Identity and Diaspora (L. Chrisman, Ed.). In P. Williams (Ed.), Colonial Discourse and Post-Colonial Theory(pp. 392-403). New York, NY: Columbia University Press.

Handa, A. (2003a). Beginnings: The Telling of Secrets. In Of Silk Saris and Mini-Skirts: South Asian Girls Walk the Tightrope of Culture (p. 1-32). Toronto, Ont.: Women's Press.

Handa, A. (2003b). Modest and Modern: Women as Markers of the Indian Nation State. In Of Silk Saris and Mini-Skirts: South Asian Girls Walk the Tightrope of Culture(pp. 53-68). Toronto, Ont.: Women's Press.

Haraway, D. (1988). Situated Knowledges: The Science Question in Feminism and the Privilege of Partial Perspective. Feminist Studies,14(3), 575.

Harding, S., \& Norberg, K. (2005). New Feminist Approaches to Social Science Methodologies: An Introduction. Signs: Journal of Women in Culture and Society,30(4), 2009-2015.

Hartman, S. (2008). Venus in Two Acts. Small Axe: A Caribbean Journal of Criticism,26, 1-14. Hashim, A. (2013). Introduction. In When Counterinsurgency Wins (pp. 1-19). Philadelphia, Pennsylvania: University of Pennsylvania Press.

Hirsch, M. (2012a). Introduction. In The Generation of Postmemory: Writing and Visual culture after the Holocaust(pp. 1-25). New York, NY: Columbia University Press.

Hirsch, M. (2012b). The Generation of Postmemory. In The Generation of Postmemory: Writing 
and Visual culture after the Holocaust (pp. 29-52). New York, NY: Columbia University Press.

Hua, A. (2005). Diaspora and Cultural Memory. In V. Agnew (Author), Diaspora, memory and identity: a search for home (pp. 191-208). Toronto: University of Toronto Press Incorporated.

Jeyarajesegaran, T. (2016, August 29). The Portrayal of Women in Tamil Cinema: Part 2. Retrieved from https://tamilculture.com/potrayal-women-tamil-cinema-part-2/

Jordan, K., \& Denov, M. (2007). Birds of Freedom? Perspective on Female Emancipation of Sri Lanka's Liberation Tigers of Tamil Eelam. Journal of Women's International Studies, 9(1), 24-62.

Kanaganayakam, C. (2007). Poetics, Language, and Genre in Contemporary Tamil Literature from Sri Lanka (R. Cheran, D. Ambalavanar, \& C. Kanaganayakam, Eds.). In History and Imagination: Tamil Culture in the Global Context(pp. 150-168). Toronto, Ont: Coach House Printing.

Kearney, R. N. (1985). Ethnic Conflict and the Tamil Separatist Movement in Sri Lanka. Asian Survey, 25(9), 898-917.

Kenny, K. (2013). Diaspora: A Very Short Introduction. New York, New York: Oxford University Press.

Laine, A. (2015). Locating art practice in the British Tamil Diaspora. World Art 5(2), 199-22.

Lakshmi, C. (1997). Bodies Called Women: Some Thoughts on Gender, Ethnicity and Nation. Economic and Political Weekly,32(46), 2953-2962.

Leavy, P. (2011). Introduction . In Oral History : Understanding Qualitative Research(pp. 4-25). New York, NY: Oxford University Press. 
Mann, Susan Archer (2012). Simultaneous and Multiple Oppressions. In Doing Feminist Theory: From Modernity to Postmodernity (pp. 178-180). New York: Oxford Press.

McKittrick, K. (2006). The Authenticity of this Story has Not Been Documented:

Auction Blocks. In Demonic Grounds: Black Women and the Cartographies of Struggle (pp. 65-90). Minneapolis: University of Minnesota Press.

Mohanty, C. T. (1984) Under Western Eyes: Feminist Scholarship and Colonial Discourses. Boundary 2, 12(3), 333-358.

Naber N. (2011). Introduction: Articulating Arabness. In Arab America: Gender Cultural Politics and Activism (pp. 1-14). New York University Press.

Palinkas, L. A., Horwitz, S. M., Green, C. A., Wisdom, J. P., Duan, N., \& Hoagwood, K. (2013). Purposeful Sampling for Qualitative Data Collection and Analysis in Mixed Method Implementation Research. Administration and Policy in Mental Health and Mental Health Services Research,42(5), 533-544.

Papastergiadis, N. (2005). Hybridity and Ambivalence. Theory, Culture \& Society, 22(4), 39-64.

Patton, M. (1990). Purposeful Sampling. In Qualitative evaluation and research methods (pp. 169-186). Beverly Hills, CA: SAGE Publications.

Rumbaut, R. G. (2006). Ages, Life Stages, and Generational Cohorts: Decomposing the Immigrant First and Second Generations in the United States. International Migration Review,38(3), 1160-1205.

Said, E. (1979). Introduction. In Orientalism (pp. 9-36). New York: Vintage Books.

Saldaña, J. (2014). Coding and Analysis Strategies. In P. Leavy (Ed.), The Oxford Handbook of Qualitative Research (pp. 581-605). New York, NY: Oxford University Press.

Satkunam, A. (2017). Major Research Project Proposal: Not Your Mother's Culture-Tamil 
Women Traversing Between Canadian and Tamil Identity and Trauma Through Art. Unpublished Paper, Ryerson University.

Shanaathanan, T. (2015). Commemorating home: Art as place making, an artist's narration. Journal of Material Culture,20(4), 415-428.

Shani, G. (2010). The Memorialization Ofghallughara: Trauma, Nation And Diaspora. Sikh Formations,6(2), 177-192.

Simpson, L. (2011). Nishnaabeg Resurgence: Stories from Within. In Dancing on Our Turtle's Back: Stories of Nishnaabeg Re-Creation Resurgence and New Emergence (pp. 85-96). Winnipeg, Manitoba: Kromar Printing.

Simpson, L. B. (2014). Land as pedagogy: Nishnaabeg intelligence and rebellious transformation. Decolonization: Indigenity, Education \& Society, 3(3), 1(25).

Sommer, D. (2004). Choose and Lose. In Bilingual aesthetics: A new sentimental Education (p. 1-28). Durham: Duke University Press.

Sugiman, P. (2004). Passing Time, Moving Memories: Interpreting Wartime Narratives of Japanese Canadian Women. Histoire Sociale/Social History,37(73), 51-79.

The Legal Case of the Tamil Genocide. (2015, January 6). Retrieved from http://hrbrief.org/wpcontent/uploads/2015/01/Legal-Case-of-the-Tamil-Genocide_30-December-2014.pdf Yuval-Davis, N. (1997). Theorizing Gender and Nation. In Gender \& Nation(pp. 1-25). London, England: SAGE Publications Ltd. 


\section{Glossary}

Bharatanatyam: A South Asian Indian classical dance form, typically reserved for women.

Miruthangam: A South Asian percussion instrument, drums, that is typically played by men.

Pottu: Also known as a bindi, it is a dot that is placed on the forehead of women. It has both cultural and religious significance. A red dot usually signifies the woman is married.

Saram: Traditional South Asian male clothing, also known as a lungi

Veena: A traditional South Asian stringed instrument typically played by women

Vibhooti: Is a sacred ash in Hinduism that is usually used to draw three horizontal lines across the forehead and others body parts. 